\title{
Mexico City during and after the September 19, 2017 earthquake: Assessment of seismic resilience and ongoing recovery process
}

\author{
A. Tena-Colunga ${ }^{1}$ (D) H. Hernández-Ramírez ${ }^{2} \cdot$ E. A. Godínez-Domínguez ${ }^{3} \cdot$ L. E. Pérez-Rocha ${ }^{4}$
}

Received: 4 May 2021 / Revised: 21 July 2021 / Accepted: 25 July 2021 / Published online: 3 August 2021

○) Springer-Verlag GmbH Germany, part of Springer Nature 2021

\begin{abstract}
Mexico City was severely affected by the September 19, 2017 Puebla-Morelos earthquake $\left(M_{w}=7.1\right)$. City authorities confirmed that more than 12,000 structures for all uses were damaged as a consequence of this earthquake. In this paper, the focus of attention is devoted to trying to quantify in a simple manner how resilient the built environment in Mexico City was during the September 19, 2017 earthquake. Global statistics compiled for the severity of damage observed during this seismic event from detailed information gathered from well-documented and detailed damage surveys were used for this purpose. Also, an update is provided on how the seismic reconstruction and recovery processes of the built environment in Mexico City have been after this earthquake. This adaptive resilience has been assessed from reliable information and statistics of the ongoing reconstruction process of the affected built environment in Mexico City. The implementation of structural health monitoring programs for typical, representative buildings within the city would be germane to detect and correct potential structural deficiencies on time before the next strong earthquake may strike, then helping to improve the seismic resilience of the built environment.
\end{abstract}

Keywords September 19 2017 earthquake $\cdot$ Seismic resilience $\cdot$ Seismic recovery $\cdot$ Reconstruction $\cdot$ Adaptive resilience

\section{Introduction}

The capital of the New Spain, now Mexico City, was founded in the former Great Tenochtitlan, a small island in the center of Lake Texcoco, which was part of a hydrological basin composed of five lakes. According to the Mexican historian Alfonso Caso [12, 13, 24], the most appealing explanation for the meaning of the word Mexico from Náhuatl language roots is: "The center of the Moon's Lake". This definition is linked to the fact that the Aztecs or Mexica Empire founded their capital in this small island which was located in Lake Texcoco, also known by the Mesoamerican cultures as the

A. Tena-Colunga

atc@correo.azc.uam.mx

1 Departamento de Materiales, Universidad Autónoma Metropolitana Azcapotzalco, Mexico City, Mexico

2 Posgrado en Ingeniería Estructural, Universidad Autónoma Metropolitana Azcapotzalco, Mexico City, Mexico

3 Facultad de Ingeniería, Universidad Autónoma de Chiapas, Tuxtla, Mexico

4 Instituto Nacional de Electricidad y Energías Limpias (INEEL), Cuernavaca, Mexico
Moon's Lake. Later, the Spanish conquerors founded their capital in the ruins of the Great Tenochtitlan Island, to display and show their power to the conquered natives. This island was flat and very small. Then, during the raining season, it was common that it was flooded. Therefore, in the early 1600 s, the Viceroy of the New Spain, Luis de Velasco, hired a German engineer which adopted the Spanish name of Enrico Martínez, to start building the Great Channel to drain Lake Texcoco towards Lake Zumpango to avoid flooding of the original island and its surroundings during the raining season. That was the beginning of opening the basin of Mexico and the progressive draining and surface drying of most of the former five lakes for the following centuries, which lead to build what it is known today as Mexico City in very soft soils with important site effects.

Most of Mexico is located in a very active seismic region. Mexico City is relatively far away from the most active and higher potential seismic sources, the subduction zone along the Mexican Pacific Coast, where the closest high-potential seismic source, a $M_{w}=8.4$ earthquake from the Guerrero Gap is close to $300 \mathrm{~km}$ from Mexico City. However, important site effects are present in Mexico City because of the political decision taken during the Spaniard colonial period 
and later in the Mexican independent era of draining most of the former natural lakes to control flood problems and also gain land for erecting the new city. Therefore, important amplifications of ground motions in the gained soft soils with respect to firm soil sites have caused uncountable severe damages and collapses in structures during past strong subduction earthquakes. The following subduction earthquakes are particularly worth noting: (a) the $M=7.8$ July 28, 1957 San Marcos Earthquake [21], $358 \mathrm{~km}$ away from Mexico City, and (b) the $M_{s}=8.1$ September 19, 1985 Michoacán Earthquake [3, 10, 23], 295 km away from Mexico City.

Continental normal faulting earthquakes may also affect Mexico City, but their considered potential has been somewhat smaller [22]. As briefly described elsewhere [28], three strongest normal faulting earthquakes $(M \geq 7)$ were felt in Mexico City since early 1970 s. However, given their distance from the epicenter, there was no important damage reported within the city at the time. Nevertheless, the recent September 19, 2017 Puebla-Morelos earthquake $\left(M_{w}=7.1\right)$, about $120 \mathrm{~km}$ away from the city, caused extensive damage. More than 12,000 structures were reported to experience from light structural damage to collapse [2, 25, 27, 28].

In following sections, a brief summary of a comprehensive post-earthquake damage assessment research of the September 19, 2017 earthquake conducted for Mexico City is offered. This post-earthquake damage assessment research is reported and discussed in greater detail elsewhere [25, 27, 28]. However, the following summary is necessary to put this paper into the right context without the need of excessive cross-referencing of information to fully understand the material which it is discussed. Then, using the data acquired in the cited research, the instantaneous drop in seismic resilience of the built environment in Mexico City during the September 19, 2017 earthquake is assessed in a simple but practical manner. Finally, updated information about the current status of the ongoing seismic recovery of Mexico City is presented and the assessment of current adaptive resilience is provided. Finally, some concluding remarks oriented mostly to the seismic resilience viewpoint are offered, where emphasis is placed on the importance of health monitoring of buildings.

\section{Observed serious structural damage in Mexico City}

As described in detail elsewhere [25, 27, 28], in a comprehensive damage reconnaissance effort using trustful information directly obtained by the authors which also integrated and processed valuable information from other reliable sources $[9,19,20], 2742$ structures were carefully cataloged, where 2458 structures experienced severe structural damage (medium or high), collapsed or have already been demolished (Fig. 1).

The geographical distribution of damaged structures within Mexico City during the earthquake is shown in Fig. 2 according to the outlined damage categories. It can be observed in Fig. 2 that most of the damaged inventory for the considered categories is within soft soils (cyan region, Fig. 2) gained to former lakes Texcoco, Xochimilco and Chalco (Fig. 3). As also shown in Fig. 2, during this earthquake a large number of buildings were demolished or experienced high or moderate damage in transition soils (white regions enclosed between the firm soils and soft soil boundaries, Fig. 2). Finally, there were also structures which experienced collapses, high or medium damage or have been already demolished in the firm soil sites of Mexico City (yellow regions, Fig. 2), mostly at the western part of the city and primarily at the hill-canyon region for the city.

The large extent of observed damage (Fig. 2) is due to several reasons which are complexly related, as described and discussed in greater detail elsewhere [25, 27, 28]. In this work, the following results are briefly shown and discussed in benefit of the understanding of the seismic resilience assessment, which is later presented and discussed: (a) use for the structure, and (b) observed spectral accelerations and their comparison with design spectra (or equivalent) of seismic codes for Mexico City.

\subsection{Structural use}

The statistics for the considered inventory for each damage category according to the main use for the structure are shown in the pie chart depicted in Fig. 4. As it can be observed in Fig. 4, the housing sector ("condo", "house" and "vecindad") was the most severely punished during this earthquake, as $78.9 \%$ of the considered inventory correspond to structures devoted to the housing sector. Within this inventory, the second most affected sector was office buildings (around 6.7\%), school buildings were third (5.2\%), commerce buildings were fourth (3.2\% overall),

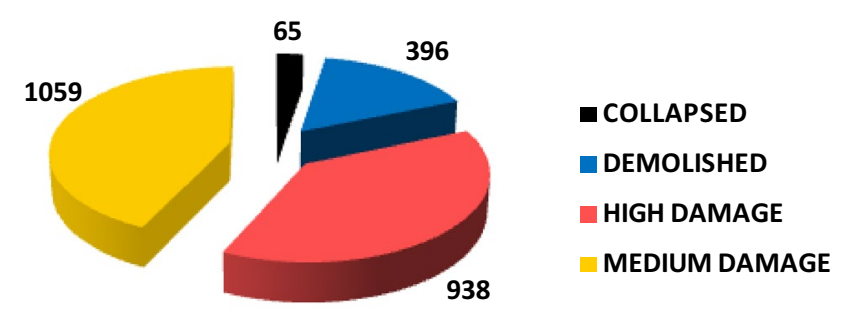

Fig. 1 Considered damage inventory of structures in Mexico City during the 2017 Puebla-Morelos earthquake 


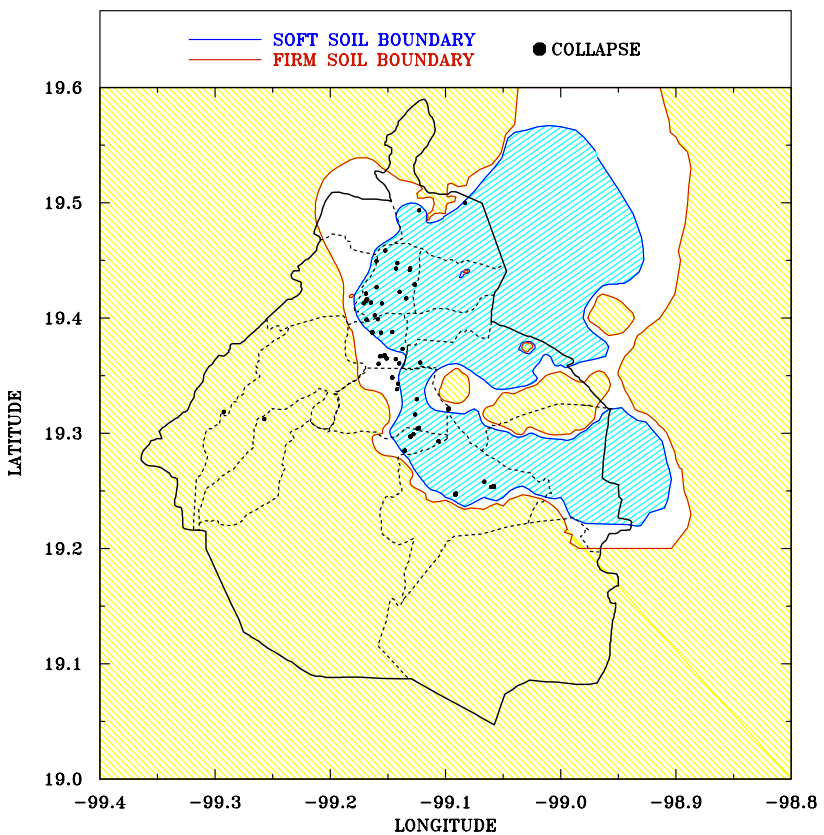

(a) Collapsed structures

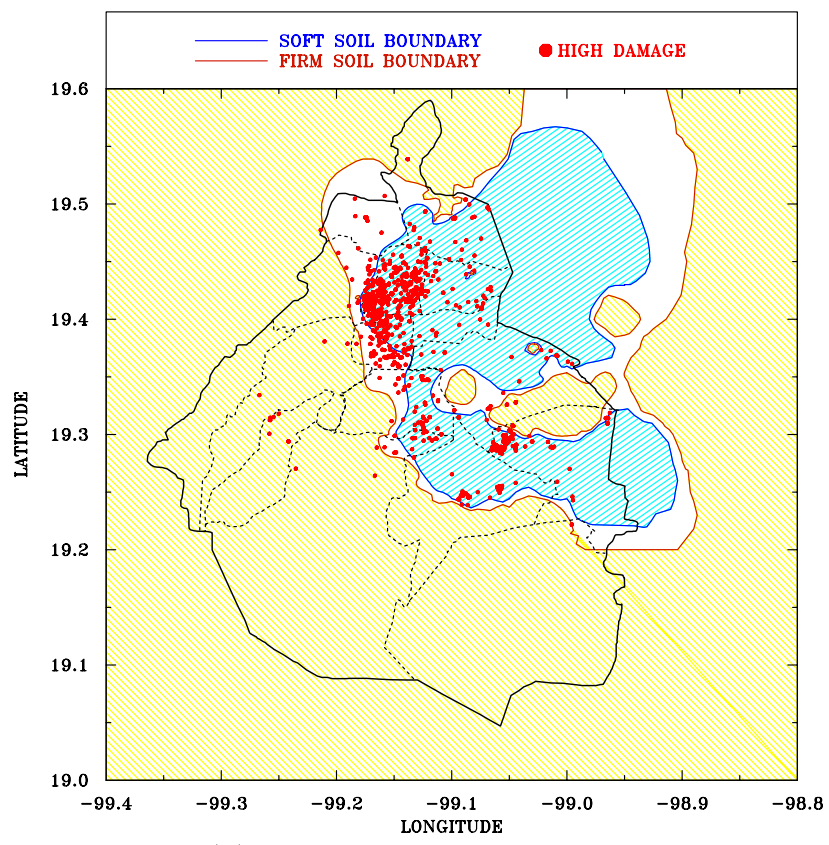

(c) Structures with high damage

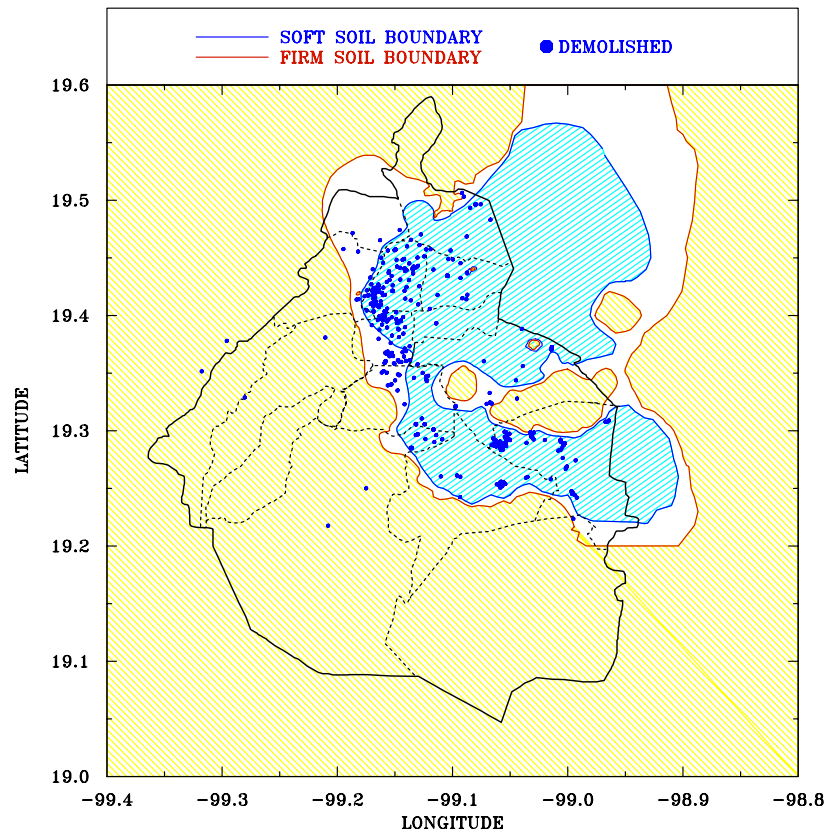

(b) Demolished structures

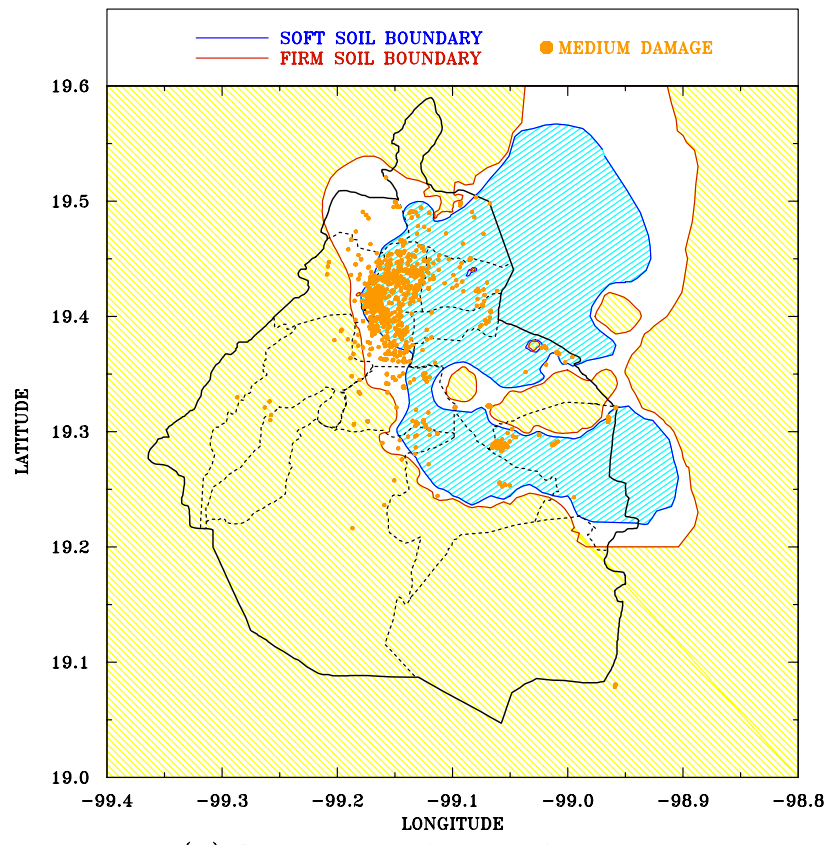

(d) Structures with medium damage

Fig. 2 Allocation of damaged structures within Mexico City in September 2017 according to their corresponding damage group

medical buildings (hospital, clinics, etc.) were fifth (1.9\%). Most hospitals were in the medium damage category $(3.1 \%)$. This was fortunate, as most of these hospitals were restored to normal operation on time to attend victims of the Covid-19 pandemic, which has affected worldwide just 30 months after the earthquake. 
Fig. 3 Recorded E-W and N-S ground motions at Mexico City during the 2017 Puebla-Morelos earthquake

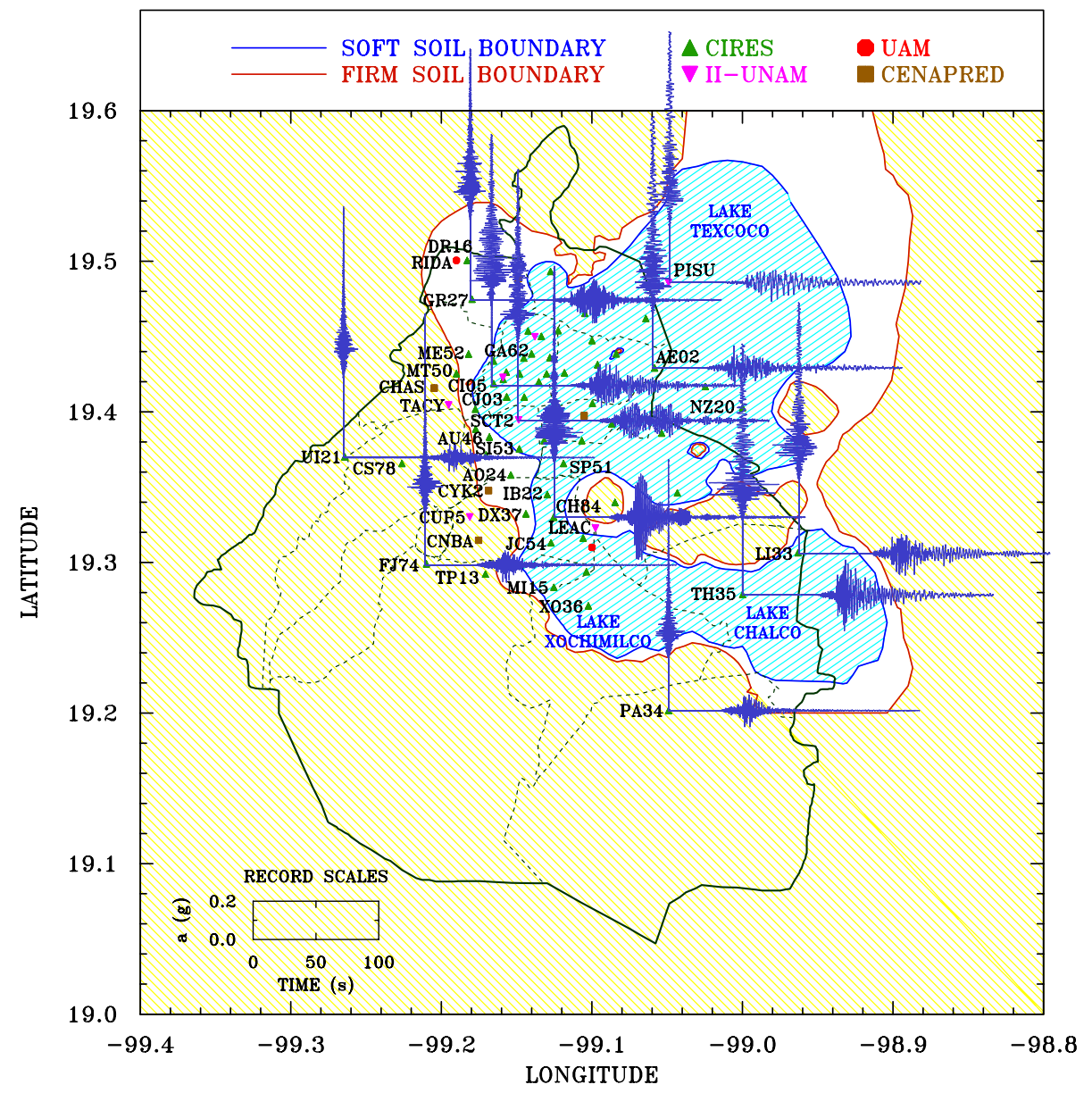

\subsection{Year of construction vs building codes design spectra}

The statistics of damaged structures with respect to the year (or era) of construction and their relationships to building codes (if any) are shown in Fig. 5. A comprehensive summary of the main seismic provisions for the building codes for Mexico City and construction practices is presented elsewhere [28]. As it can be observed from Fig. 5, the vast majority of collapses and severely damaged structures corresponded to old, working stress design (WSD) seismic codes for Mexico City (1942-1966), particularly for the 1966 code. However, there were also many damaged buildings for collapse-prevention codes (1976-2004), particularly for the 1976 code. The vast majority of damaged buildings, collapsed and demolished buildings were found for the 1966 and the 1976 codes. Why? Among the coincident reasons were: (a) Mexico City has more old buildings erected in that time frame (1966-1985), as a consequence of demographic and construction grew up, and (b) the effective design base shear for the 1966 code and the 1976 code was almost the same for all structural systems, although a better shear detailing for RC structures was set in the 1976 code.
To correlate the geographical distribution of damage (Fig. 2) with the ground motions recorded on the available stations (Fig. 3), the building codes (Fig. 5), the number of stories (e.g., [28] and the primary use for the structure (Fig. 4), response spectra were computed for recorded ground motions for different soil profile types. Then, response spectra for selected recorded ground motions are compared with the elastic design spectra for all the seismic codes of Mexico City in Figs. 6, 7, 8 for a considered common structural use (apartment, office or commerce buildings). The four-letter tags for most considered stations are identified in the map shown in Fig. 3, to connect their geographical location and the reported damage (Fig. 2).

Elastic response spectra obtained from recorded ground motions are contrasted with the corresponding design spectra for buildings codes from 1942 to 2004 for firm soils in Fig. 6, for transition soils in Fig. 7 and for soft soils in Fig. 8. With the aim of giving a better frame of comparison with the geographical distribution of damage depicted in Fig. 2 and the ground shaking shown in Fig. 3, in firm soils (Fig. 6), stations were ordered depending their closest geographical location in south, central-west and west, according to what it is shown in Fig. 3. 


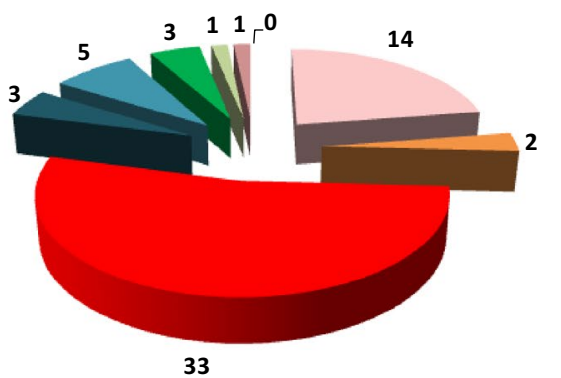

(a) Collapsed structures

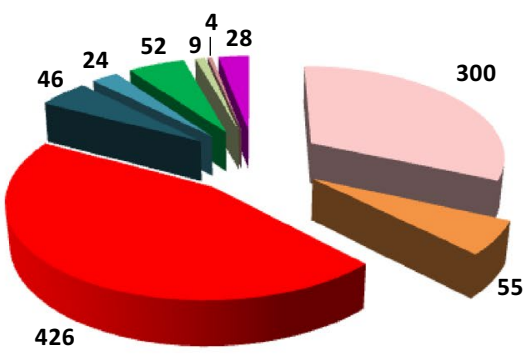

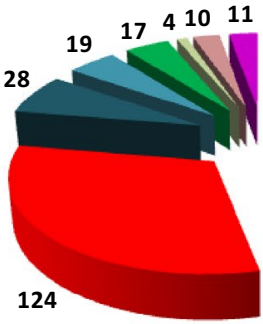

- OTHER

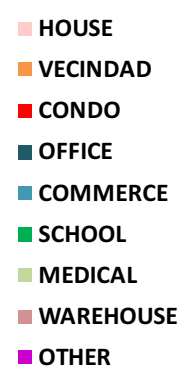

VECINDAD

- COMMERCE

- SCHOOL

MEDICAL

(1)



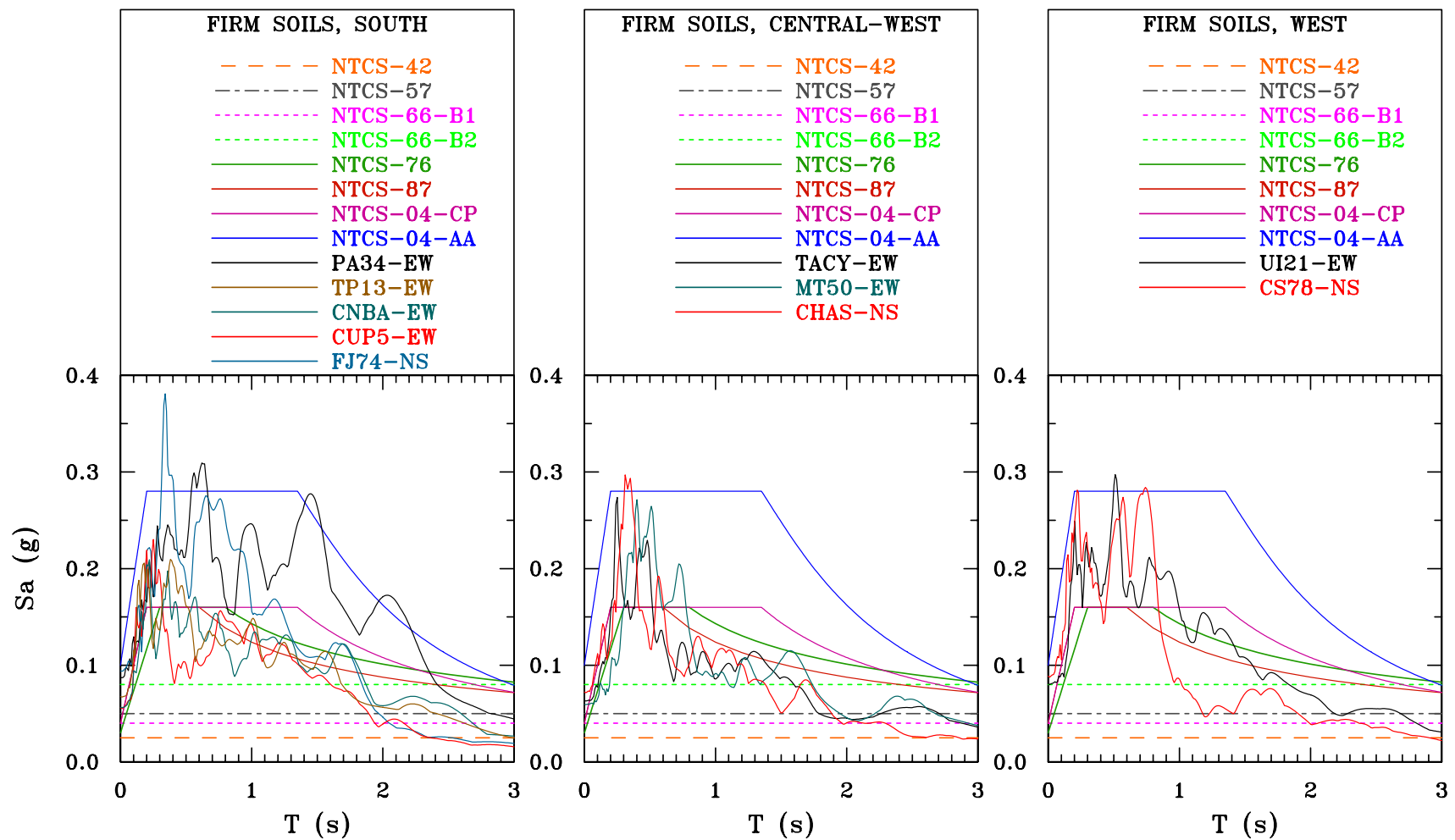

Fig. 6 Comparison of elastic response spectra for selected firm soils records in Mexico City for the 2017 Puebla-Morelos earthquake with the related elastic design spectra for the different seismic buildings codes for Mexico City (1942-2004)
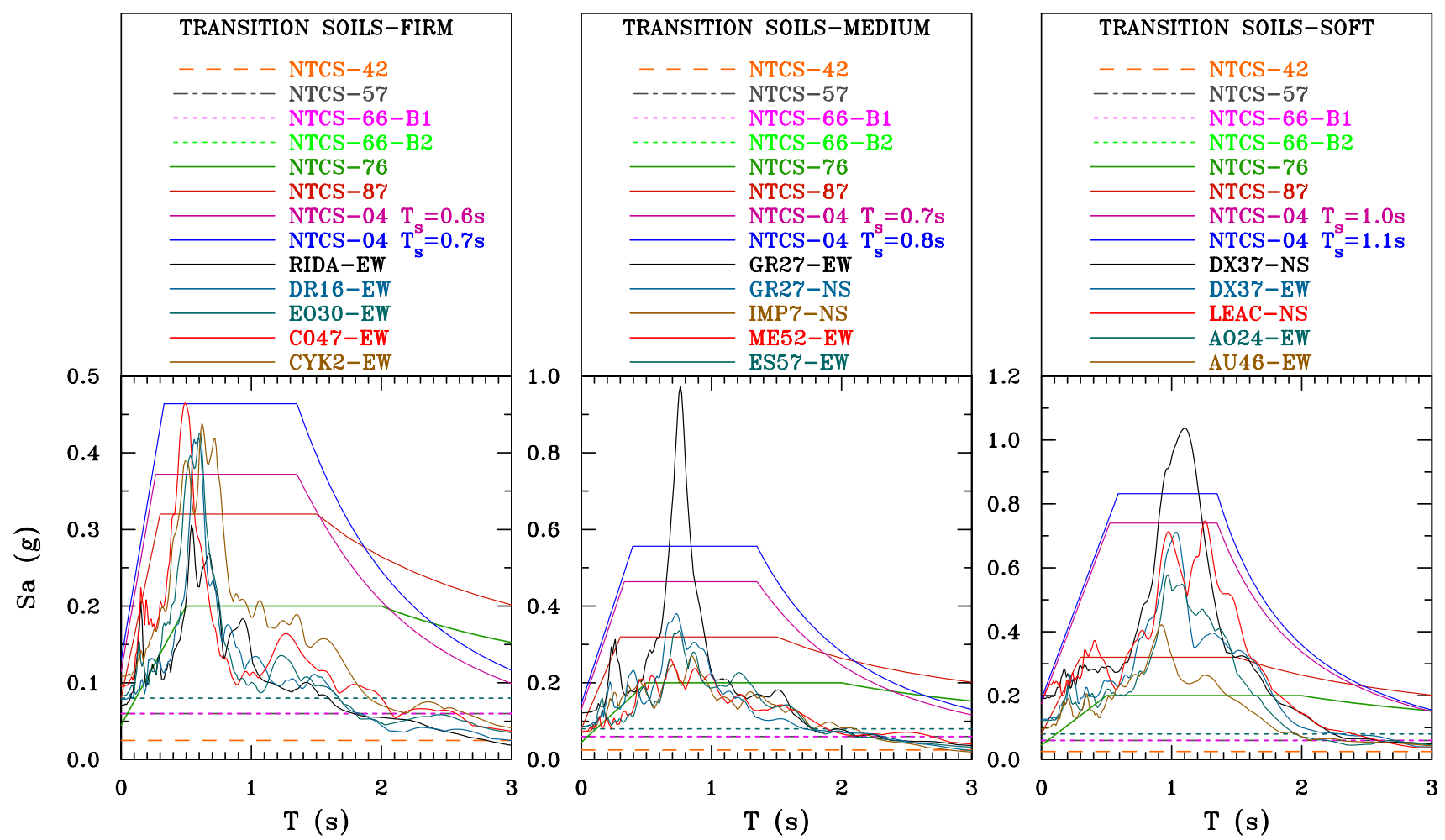

Fig. 7 Comparison of elastic response spectra for selected transition soils records in Mexico City for the 2017 Puebla-Morelos earthquake with the related elastic design spectra for the different seismic buildings codes for Mexico City (1942-2004) 

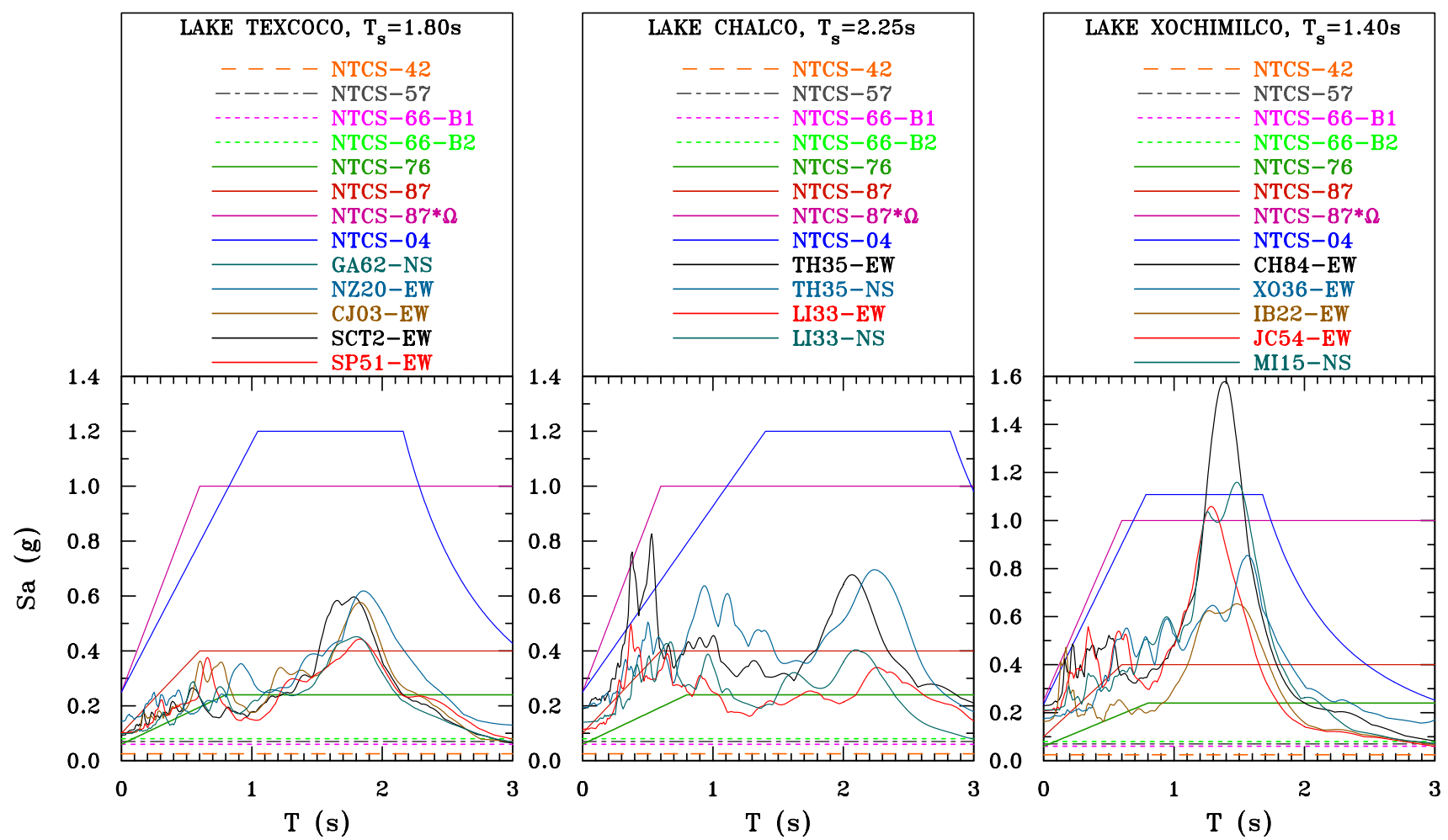

Fig. 8 Comparison of elastic response spectra for selected soft soils records in Mexico City for the 2017 Puebla-Morelos earthquake with the related elastic design spectra for the different seismic buildings codes for Mexico City (1942-2004)

the 1976 code and ending with the 1942 code. Then, the observed extent of damage in transition soils (Fig. 2) and the statistics for year of construction (Fig. 5) correlate well with this spectral information. The design spectrum for the 1987 code [15] was surpassed by those of the recorded motions located at: (a) "transition soil-firm" soils, at the west and south-center of Mexico City in Benito Juárez and Coyoacán Districts (Fig. 3), where damage was observed (Fig. 2), (b) "transition soil-medium" soils, only at station GR27, at the north of the city (Fig. 3), where moderate and high damage were observed, and some buildings were demolished (Fig. 2), and (c) "transition soils-soft" soils, where NTCS-87 design spectrum was considerably surpassed. Therefore, in conclusion, the extent of damage observed within transition soils (Fig. 2) should be anticipated, as the design spectra for most seismic codes (1942-1987) were surpassed, in particular older codes, where they were substantially exceeded.

Given that site periods vary widely in soft soils, elastic response spectra obtained from ground motions recorded in soft soils were computed for the zones where more damage was observed (Fig. 2) and where some representative records were available (Fig. 3). Therefore, for Lake Texcoco, a site period $T_{s}=1.80 \mathrm{~s}$ was considered in Fig. 8, which covered most of the western part (stations GA62, CJ03 and SCT2) one in the center (station SP51) and one in the east (station
NZ20). It can be observed in Fig. 8 that the design spectra for the 1942 to the 1976 codes were exceeded by the response spectra associated to these ground motions, so the severe damage detected for those codes in that region was expected (Fig. 2). However, it can also be viewed in Fig. 8 that the real design spectrum for the 1987 code (NTCS$87 * \Omega$ ) and the one for the 2004 code [16] covered well the response spectra, as design accelerations were more than the double of the peak ones recorded at those locations.

For Lake Chalco, a site period $T_{s}=2.25 \mathrm{~s}$ was considered and similar observations can be done: spectral accelerations considerably exceeded those of the codes from 1942 to 1976, but they were mostly covered by those of the 1987 and 2004 codes. Since this region was not very crowded before the 1985 earthquake, the damage detected in buildings here was much smaller in numbers and it was mainly for those buildings erected according to the 1976 and 1987 codes. However, it is worth noting that most of the severe damage and collapses in single-family houses were exactly in this zone [25, 27].

For Lake Xochimilco, $T_{s}=1.40 \mathrm{~s}$ was considered, and it can be viewed in Fig. 8 that older codes (1942-1976) were considerably exceeded. Although the "real" design spectrum for the 1987 code (NTCS-87* $\Omega$ ) and the 2004 code spectrum [16] mostly comprised all ground motions, the 1987 
code was exceeded by three records: JC54-EW, MI15-NS and CH84-EW, and the 2004 code mainly by CH84-EW, the strongest record for this earthquake and the strongest one recorded in the soft soils in Mexico City attending to their peak ground acceleration $\left(a_{\max }=0.23 \mathrm{~g}\right)$ and peak spectral acceleration for an assumed equivalent viscous damping of $5 \%$ the critical $\left(S_{a-\max }=1.58 \mathrm{~g}\right)$. In this zone, severe damages and collapses were more than justified and should be anticipated, but given that this region started to be populated importantly in the late 1960s, most of the damage catalog is for buildings erected for 1966, 1976 and 1987 codes, and only few for the 1995 and 2004 code [28].

Finally, it can be concluded that the amount of severe damage detected in Mexico City can be explained by the spectral intensity of the ground motions when putting in context to those considered by the design spectra of the seismic codes before the 1985 earthquake: the 1942, 1957, 1966 and 1976 codes. In some regions of firm, transition and soft soils (Lake Xochimilco primarily), the damage occurred because spectral intensities for the recorded ground motions also surpassed the design spectra for the 1987 and 2004 codes. The disappointing and surprising news was the extent of damage and even collapses which were observed in some buildings designed primarily according to the 1987 and 2004 codes in the soft soils of Lake Texcoco [25, 27, 28], where the design spectra covered well the strongest ground motions recorded there (Fig. 8). A serious analysis and criticism is currently being done by the Mexican earthquake engineering community regarding minimum seismic code design processes and requirements. Currently, it is being discussed if a collapse-prevention design scenario is still good enough for the seismic design of future "new" buildings, or serious steps should be taken to move forward code design methodologies to resilient-based seismic design, in order to minimize building damage and societal recovery.

\section{Assessment of instantaneous drop of seismic resilience for Mexico City}

As noted and discussed in detail elsewhere [2, 25, 27, 28], and briefly discussed in previous sections, the observed important damage in structures in Mexico City was extensive during the September 19, 2017 earthquake, given the intensities of the recorded ground motions. In this section, the authors want to do the following reflections: (a) how resilient was the built environment in Mexico City before the September 19, 2017 earthquake?, (b) so far, how has been the seismic recovery process of the built environment in Mexico City after the earthquake and, (c) how could the seismic resilience of the built environment be improved before the next strong earthquake strikes Mexico City? As resilience may have different definitions depending on the focus of interest, the authors would discuss it in terms of definitions more related to structural systems from the earthquake engineering viewpoint $[4,7,26]$.

Mexico City is an old city with a large inventory of structures (buildings and houses or dwellings) with the following characteristics and shortcomings [25, 27, 28]. It should be considered that many of them: (a) were built before the existence of seismic buildings codes, (b) were designed with seismic codes which design spectra historically have
Fig. 9 Proposed measurement for the seismic resilience of the built environment for an ancient city with a large inventory of existing structures built before modern seismic code like Mexico City. Modified and adapted from the more general original proposals by Bruneau et al. [4] and Cimellaro et al. [7]

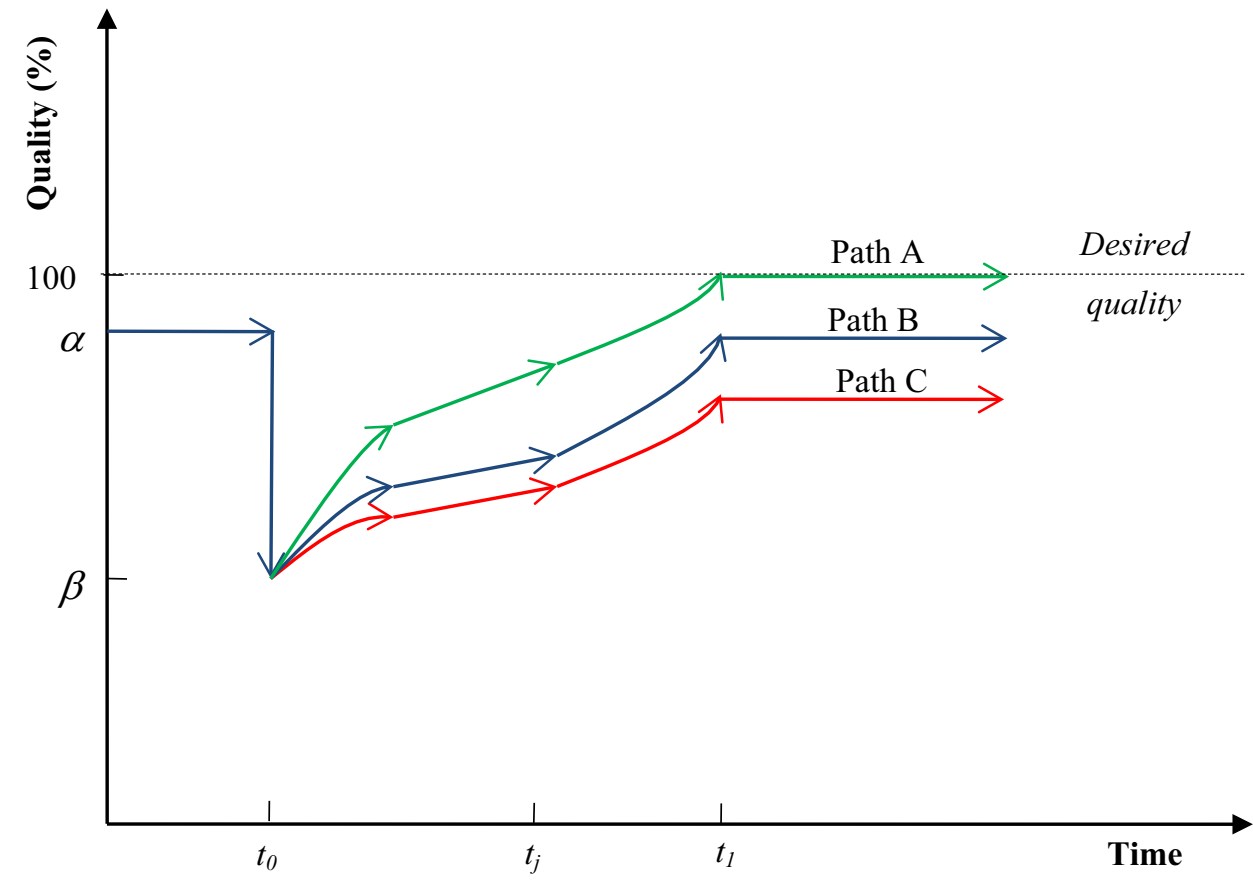


been considerably exceeded by the spectral accelerations of many records for both subduction earthquakes (September 19,1985 ) and normal faulting earthquakes (September 19, 2017), (c) possess important deterioration, previous damage and previous tilting, (d) were built using self-construction techniques, (e) are founded in very soft and weak soils prone to experience subsidence $[1,6]$, as well as differential and sudden soil settlements, (f) have several conditions of structural irregularities, $(\mathrm{g})$ are weakly redundant, and $(\mathrm{h})$ were designed with modern collapse-prevention seismic codes assuming large reduction factors to account for "stable" inelastic deformations. Therefore, for all these shortcomings, in the opinion of the authors, the inherent seismic resilience [5] or quality of infrastructure [4] for the building inventory in Mexico City before the September 19, 2017 earthquake cannot be considered "optimal" or $100 \%$ [4, 7]. Instead, more rationally, it should be considered a fraction of it, named here $\alpha$ (Fig. 9), given the large inventory of existing old structures (built before 1987) which design spectra was considerably surpassed all over Mexico City by the response spectra of the recorded ground motions (Figs. 6, 7, 8). This more realistic hypothesis does not apply to Mexico City only, but many old, historical cities in seismic zones which may have some of the outlined deficiencies described above, or some additional ones.

How large $\alpha$ was for Mexico City to survive successfully the September 19, 2017 earthquake? To answer properly this question, several formal vulnerability-resilient assessment analyses would be required for a given earthquake scenario of interest (with many hypothesis and simplifications as well), which are beyond the scope of this paper. However, optimistically, one may consider that it may be close to $85 \%$ ( $\alpha=85 \%$ ) for an earthquake of this magnitude, seismic source ( $\alpha$ should also depend also on the magnitude and distance from the seismic source) and the important site effects in the lakebed regions of Mexico City.

Given the extensive observed damage, as shown and discussed here, the quality of the infrastructure dropped to $\beta$ (Fig. 9). The reported extent of damage in the built environment was large; city authorities confirmed a total of 12,253 damaged structures [2] including all categories (from lightly damaged to collapses and demolitions). However, according to the public cadastre database [8], in 2019, there were about 1,048,575 structures (houses, buildings, etc.) registered in Mexico City. Then, assuming that the real number of damaged structures (including those not counted by the city authorities) is, in rough numbers 15,700 , and at the time of the earthquake there were 1,048,500 structures, then roughly $1.5 \%$ of the existing built environment inventory was affected.

However, it would be naive to consider that the seismic resilience in the built environment in Mexico City only dropped $1.5 \%$ after the 2017 earthquake, as most of the structures registered in the cadastre are single-family houses. A more rational approach would be to compute: (a) how many single housing units (single houses, apartments in buildings or in "vecindades") were affected with respect to the total inventory of such use, and (b) assessing the same relative numbers for buildings and structures for other uses (office, commerce, school, medical, etc.) in terms of the most rational available parameter there (total floor area, average number of people using the building, etc.). As most of the relevant information needed to perform such calculations unfortunately is not public, the authors are unable to get a rational number using this proposed rational approach.

Alternatively, the following intuitive-yet arbitrarymeasurement is also proposed to estimate an equivalent number of affected structures $\left(N_{e q}\right)$, in terms of the extent of medium damage to collapse observed and their use, for the considered inventory of damaged structures, according to the detailed inventory compiled (Figs. 2, 4). Then, one can crudely assess an equivalent number of single-family houses $\left(N_{e q H}\right)$, "vecindades" $\left(N_{e q V}\right)$, apartment buildings $\left(N_{e q A B}\right)$, office buildings $\left(N_{e O F}\right)$, school buildings $\left(N_{e q S C H}\right)$, medical buildings $\left(N_{e q M B}\right)$ and buildings with other uses $\left(N_{e q O U}\right)$, as follows:

$N_{e q}=N_{e q H}+N_{e q V}+N_{e q A B}+N_{e q O F}+N_{e q S C H}+N_{e q M B}+N_{e q O U}$

$N_{e q H}=N_{H-c d} C_{c d}+N_{H-h d} C_{h d}+N_{H-m d} C_{m d}$

$N_{e q V}=a_{1-c d} N_{V-c d} C_{c d}+a_{1-h d} N_{V-h d} C_{h d}+a_{1-m d} N_{V-m d} C_{m d}$

$N_{e q A B}=a_{2-c d} N_{A B-c d} C_{c d}+a_{2-h d} N_{A B-h d} C_{h d}+a_{2-m d} N_{A B-m d} C_{m d}$

$N_{e q O F}=a_{3-c d} N_{O F-c d} C_{c d}+a_{3-h d} N_{O F-h d} C_{h d}+a_{3-m d} N_{O F-m d} C_{m d}$

$N_{e q S C H}=a_{4-c d} N_{S C H-c d} C_{c d}+a_{4-h d} N_{S C H-h d} C_{h d}+a_{4-m d} N_{S C H-m d} C_{m d}$

$N_{e q M B}=a_{5-c d} N_{M B-c d} C_{c d}+a_{5-h d} N_{M B-h d} C_{h d}+a_{5-m d} N_{M B-m d} C_{m d}$

$N_{e q O U}=a_{6-c d} N_{O U-c d} C_{c d}+a_{6-h d} N_{O U-h d} C_{h d}+a_{6-m d} N_{O U-m d} C_{m d}$,

where $N_{H-x x}$ is the number of singles houses for the damage category $x x ; N_{V-x x}$ is the number of "vecindades" for the damage category $x x$ and $a_{1-x x}$ is the average number of dwellings per "vecindad" in the damage category $x x ; N_{A B-x x}$ is the number of apartment buildings for the damage category $x x$ and $a_{2-x x}$ is the average number of apartments per building in the damage category $x x ; N_{S C H-x x}$ is the number of school buildings for the damage category $x x$ and $a_{4-x x}$ average number of affected families per school building in the damage category $x x . N_{M B-x x}$ is the number of medical buildings for the damage category $x x$ and $a_{5-x x}$ average number of affected families 
per medical building in the damage category $x x \cdot N_{O F-x x}$ is the number of office buildings for the damage category $x x$ and $a_{3-x x}$ average number of affected families per office building in the damage category $x x . N_{O U-x x}$ is the number of buildings with other uses for the damage category $x x$ and $a_{6-x x}$ is the average number of affected families per building in the damage category $x x$.

The proposed constants which affect these sums are: (a) $C_{c d}$, a constant which assesses the loosing and back to normal impact for structures in the collapsed and demolished categories (in terms of an estimated average number of years); $C_{c d}=3$ is proposed; (b) $C_{h d}$, a similar constant for structures in the high damage category; $C_{h d}=2$ is proposed; and (c) $C_{m d}$, a similar constant for structures in the medium damage category; $C_{m d}=1$ is proposed.

For "vecindades", in sake of simplicity, an average number of 8 dwellings per "vecindad" was considered, this is, $a_{1-c d}=a_{1-h d}=a_{1-m d}=8$. For buildings of other use (primarily commerce buildings, warehouses, stores, etc.), a constant factor $a_{6-c d}=a_{6-h d}=a_{6-m d}=30$ was considered.

For apartment buildings, the constant $a_{2-x x}$ for each damage category is crudely assessed as follows:

$a_{2-x x}=4 N_{s a-x x}$,

where $N_{s a}-x x$ is the average number of stories per building in the damage category $x x$, and 4 is an assumed average number of apartments per story per apartment building. It is worth noting that depending on the size of the building, the year of construction and the quality of the residential district, the number of apartments per story range from one (luxury apartment buildings) up to 10 (large building apartment complexes with small-area apartments). Finally, similar proposals are done for other building categories (Eqs. 10, $11,12)$, as the proposed factors take into account the higher impact on affected families for the momentarily loss of use for office, school, and medical buildings.

$a_{3-x x}=20 N_{s a-x x}$

$a_{4-x x}=80 N_{s a-x x}$

$a_{5-x x}=100 N_{s a-x x}$.
Using Eqs. 1-12 and the reported data summarized in Table $1, N_{e q}=161,994$ was assessed, which in relative terms of the existing cadastre of structures for Mexico City, represents a $15.45 \%$ sudden drop of the seismic resilience in the built environment in Mexico City after the September 19, 2017 earthquake, then $\beta \approx 69.55 \%$ (Fig. 9).

\section{Ongoing recovery process or adaptive resilience in Mexico City}

The recovery process or adaptive resilience [5] for the affected built environment in Mexico City has been naturally slow, given the very large number of seriously affected structures and the very large investment needed to retrofit them or to replace them. The speed of the adaptive resilience process is also different for each sector. For example, there is always more social pressure and then prompt government actions to recover quickly public facilities such as schools, hospitals and other infrastructure (airport, bus terminals, etc.) and the housing sector, rather than office buildings (even public offices), commercial or religious buildings, for example.

Under this perspective, perhaps the most transparent effort done by the Mexican society and city authorities has been conducted to attend and document the recovery process for the housing sector (houses, apartment buildings and "vecindades"), as it was the most severely affected (Table 1; Fig. 4). Then, from the data reported by city authorities in their reconstruction site [20], up to March 16 2021 (42 months after the earthquake), from a universe of 370 apartment buildings projected to be recovered, in 135 of them $(36.5 \%)$ their retrofitting or rebuilding processes have been already finished, and in 95 of them $(25.7 \%)$ reconstruction works are still in progress. The remaining inventory is still in project (125 or 33.8\%) or administrative process (15 or $4.1 \%)$. From a universe of additional 103 apartment buildings corresponding to 8 large housing complexes to be recovered, $76(73.3 \%)$ are under reconstruction processes, 15 (14.6\%) are under administrative processes and the remaining $12(11.7 \%)$ are under ongoing formal retrofit or design projects. Therefore, from the global statistics for apartment buildings (belonging or not to large housing complexes), it can be observed (Fig. 10a) that up to March 16 2021, from 473 apartment buildings which are going to be recovered
Table 1 Considered inventory of damaged structures in Mexico City

\begin{tabular}{|c|c|c|c|c|c|c|c|c|c|c|c|c|}
\hline \multirow[t]{2}{*}{ Damage Tag } & \multirow{2}{*}{$\begin{array}{l}\text { House } \\
N_{H}\end{array}$} & \multirow{2}{*}{$\begin{array}{l}\text { "Vecindad" } \\
N_{V}\end{array}$} & \multicolumn{2}{|c|}{ Apartment } & \multicolumn{2}{|c|}{ Office } & \multicolumn{2}{|c|}{ School } & \multicolumn{2}{|c|}{ Medical } & \multirow{2}{*}{$\begin{array}{l}\text { Other } \\
N_{O U}\end{array}$} & \multirow[t]{2}{*}{ Total } \\
\hline & & & $N_{A B}$ & $N_{s a}$ & $N_{O F}$ & $N_{s a}$ & $N_{S C H}$ & $N_{s a}$ & $N_{M B}$ & $N_{s a}$ & & \\
\hline$c d$ & 170 & 27 & 157 & 6.26 & 31 & 6.55 & 20 & 3.50 & 5 & 5.20 & 51 & 461 \\
\hline$h d$ & 298 & 55 & 425 & 6.07 & 46 & 7.61 & 52 & 2.54 & 7 & 6.29 & 55 & 938 \\
\hline$m d$ & 212 & 27 & 570 & 6.38 & 89 & 8.57 & 56 & 2.54 & 33 & 4.36 & 72 & 1059 \\
\hline Sum & 680 & 109 & 1152 & & 166 & & 128 & & 45 & & 178 & 2458 \\
\hline
\end{tabular}




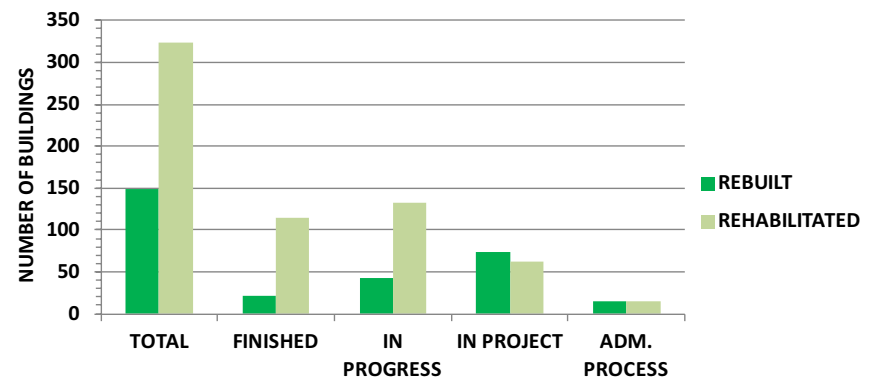

(a) Statistics, apartment buildings

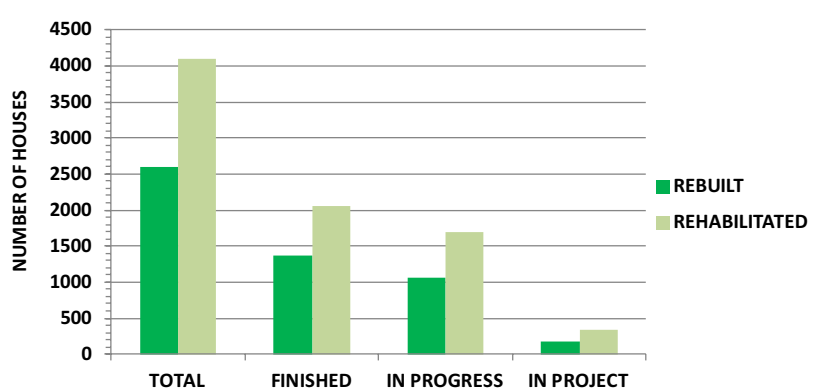

(b) Statistics, houses and "vecindades"

Fig. 10 Summary of the reconstruction or recovery processes coordinated by Mexico City authorities for housing, according to the data reported in the web site Reconstrucción CDMX up to March 16, 2021

(149 to being rebuilt and 324 to being rehabilitated either with strengthening or retrofit strategies), in only 135 (28.5\% of this total) recovery processes have been completed. From a universe of 6943 houses and "vecindades" that have been attended (Fig. 10b), which include more than 6000 houses which experienced small damage (green category, not shown in our damage statistics in Fig. 4 and Table 1), 3430 of them (49.4\%), their retrofitting or rebuilding processes have been already finished, in 2740 of them $(39.5 \%)$ reconstruction works are still in progress. However, in 509 (7.3\%) reconstruction processes have yet not been started and in 264 of them $(3.8 \%)$ rehabilitation processes have not been defined or relocation to other site is being evaluated (these 264 houses are not included in Fig. 10b).

According to city authorities, from the public trust fund for reconstruction [20] up to the end of February 2021, close to 3978 million Mexican pesos (193.2 million US dollars) have been spent in the reconstruction of the housing sector shown above (Fig. 10), from a total available budget of around 5335 million Mexican pesos (259.77 million US dollars). To this amount, it should be added the reconstruction trust fund effort leaded by the private sector, which also incorporate donations from the solidarity of Mexican citizens [11], where up to the end of December 2020, around 1815 million Mexican pesos (88.4 million US dollars) have been spent in the reconstruction of the housing sector. Therefore, approximately 5793 million pesos (281.6 million US dollars) have been spent in the reconstruction of the housing sector in Mexico City up to February 2021.

Despite the fact of this great coordinated effort by city authorities and the private sector for the reconstruction of housing, it can be observed (e.g., Fig. 10) that it is not enough yet, given the large number of affected buildings for the housing sector. As it is reported in Table 1, at least 1152 apartment buildings experienced from medium damage to collapse. The coordinated reconstruction effort is attending 473 apartment buildings in total, that is, $41.1 \%$ of the total of seriously affected apartment buildings. That it is why city authorities estimate that they need at least other $\$ 7000$ million Mexican pesos (341 million US dollars) to finish their reconstruction effort for the housing sector in Mexico City. Of course, much more funds are needed to attend properly all affected apartment buildings (the remaining 679 or more which are not included in this coordinated city effort). For these reasons, one can see the scenes in Mexico City in the recovery process (Figs. 11, 12, 13, 14, 15, 16, 17, 18, 19) described in the following section, which one has to say also, the COVID-19 pandemic has also slow down a little bit. Construction activities have been affected by the COVID19 pandemic in different time frames, when city authorities ordered to stop or reduce the activities of some economic sectors which were considered "no essential", specially at the beginning of the pandemic (from March to July 2020), and when viral outbrakes considerably increased, for example, recently in January 2021.

The reconstruction effort for public schools has been a little bit hermetic and less transparent to the general public, but excellent results have been obtained so far. According to city authorities [20], from 2046 public schools in Mexico City which experienced damage or were found with important signs of deterioration (not all of them really related to the earthquake, but inadequate maintenance and aging), up to the end of February 2021, 1977 (96.7\%) were completely rehabilitated and 49 are under recovery process, spending 2379 million pesos (115.5 million US dollars). The private sector has collaborated so far with the rehabilitation or retrofit of 190 of these schools of Mexico City [11], and spent approximately additional 268 million pesos (13.0 million dollars). Therefore, the total money spent for the recovery of public schools in Mexico City is so far 2647 million pesos (128.5 million US dollars). Regarding the private school sector, actions are even more hermetic, particularly regarding the money spent on the recovery actions. The two collapsed buildings of the well-known Colegio Rebsamen (a tragedy where 26 students died) are still in the same 


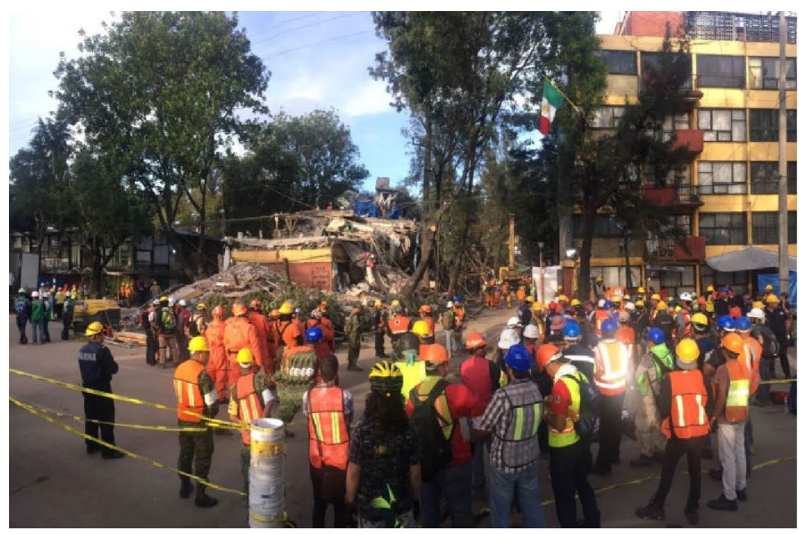

(a) September 19, 2017

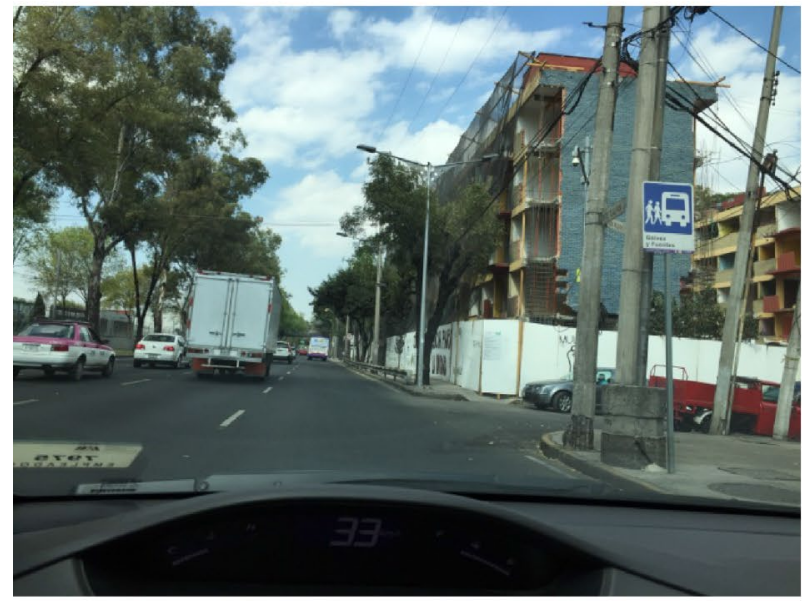

(c) December 10, 2018

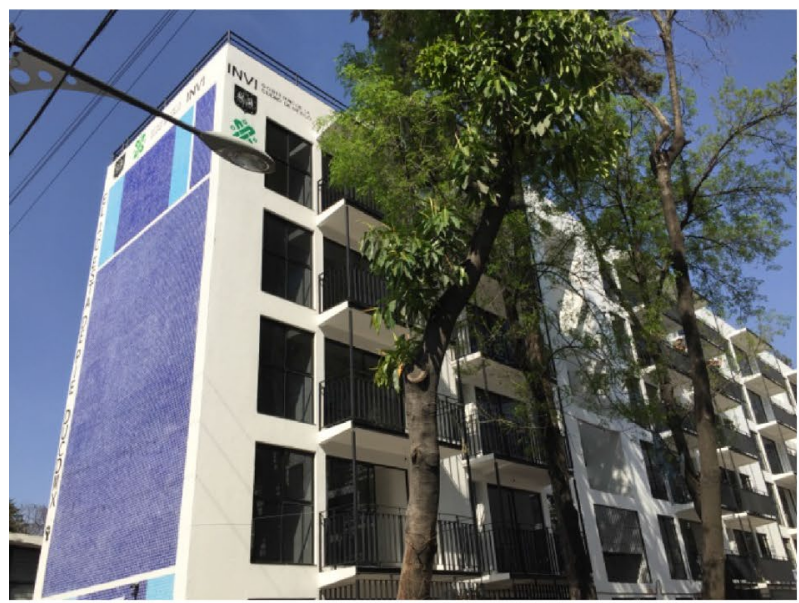

(e) February 8, 2020

Fig. 11 Multifamiliares Conjunto Urbano Tlalpan housing complex. a Collapse of 1-C building, $\mathbf{b}$ demolition process of 1-C building, $\mathbf{c}$ initial works toward the strengthening of other similar buildings, $\mathbf{d}$

collapsed status as in September 19, 2017, because serious legal issues should be solved first. Some of the damaged buildings at Tecnológico de Monterrey CDMX campus were demolished. New replacement buildings are currently under

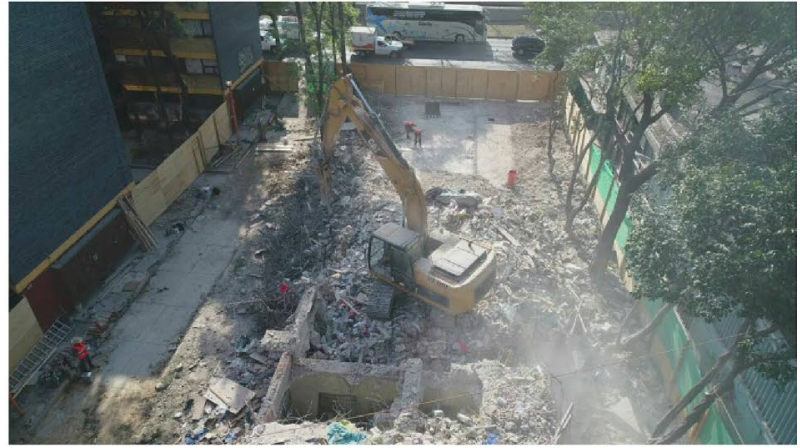

(b) January 20, 2018

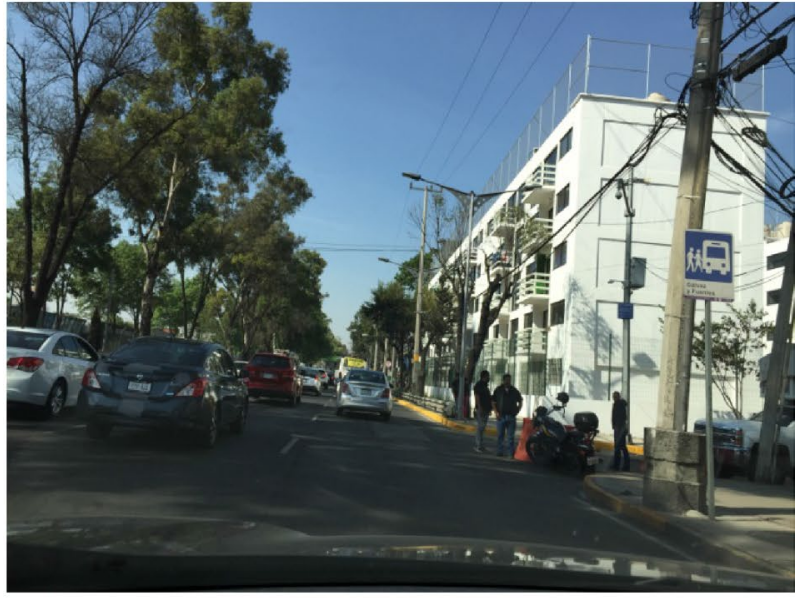

(d) February 8, 2020

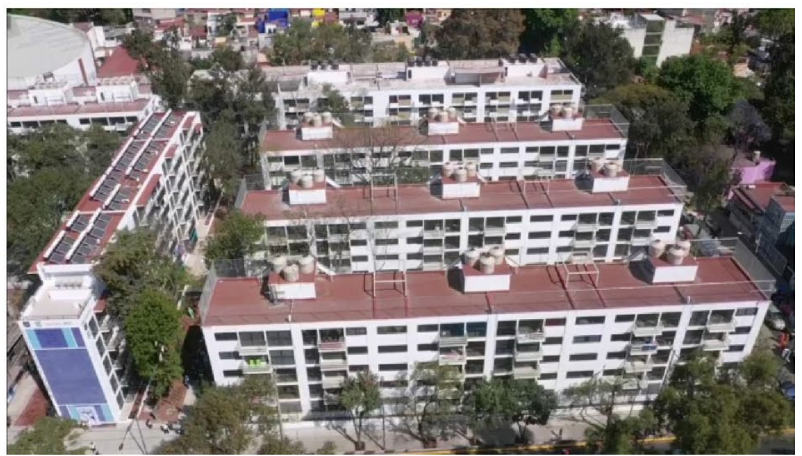

(f) February 8, 2020

finished strengthening project of similar buildings, e newly erected 1-C building, and $\mathbf{f}$ global view of the completely rehabilitated Multifamiliares Conjunto Urbano Tlalpan housing complex

construction process which may end at the end of 2021 or beginning of 2022 . Others private school buildings have been already recovered. 


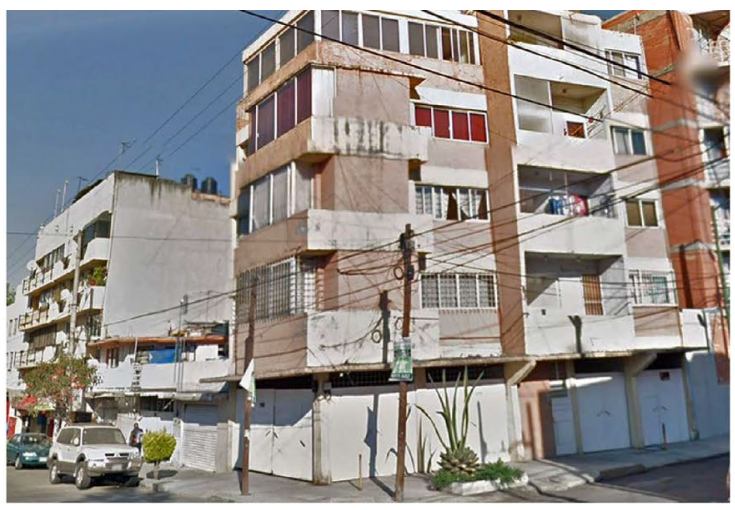

(a) Before September 19, 2015

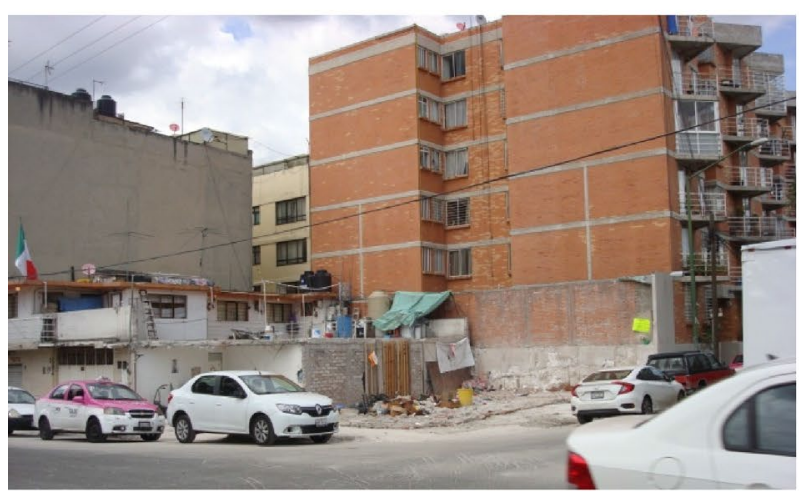

(c) September 24, 2017

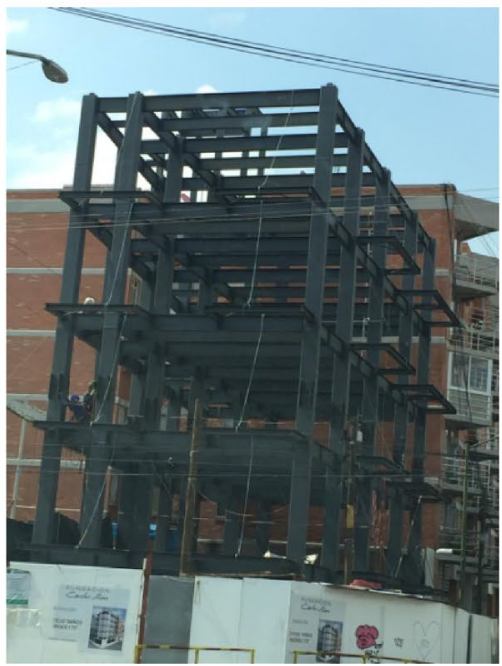

(e) May 20, 2020

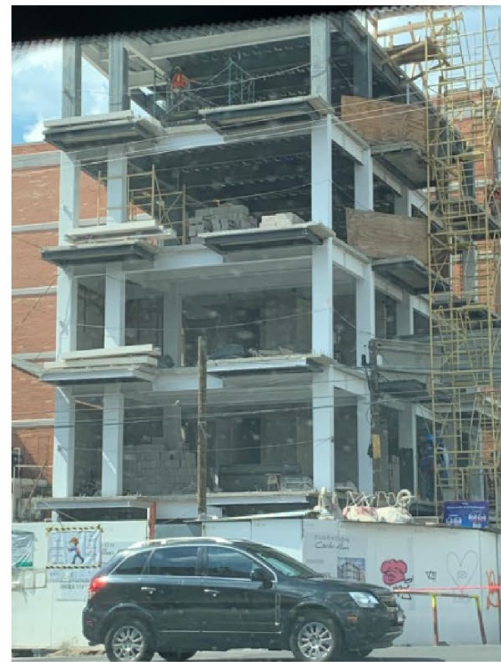

(f) September 25, 2020

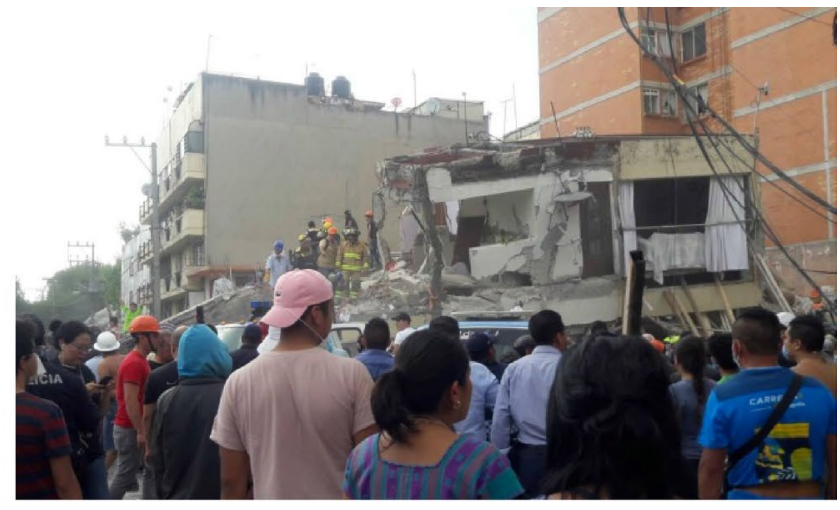

(b) September 19, 2016

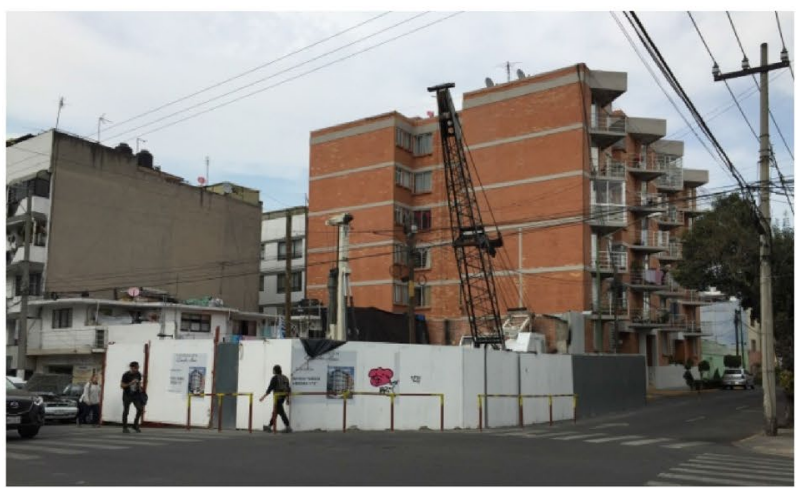

(d) November 1, 2019

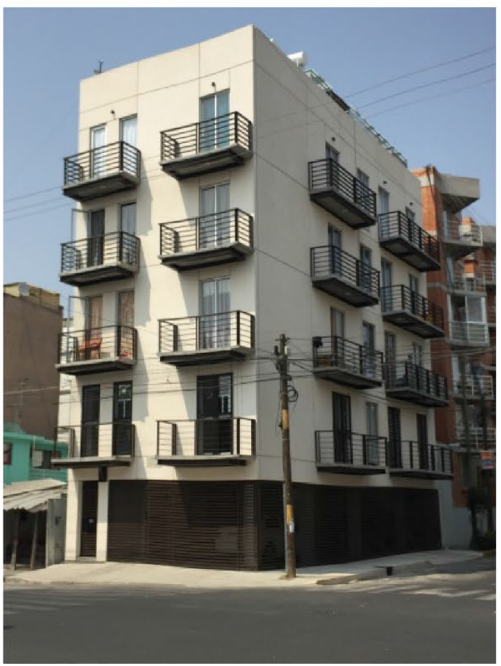

(g) March 6, 2021

Fig. 12 Niños Heroes 173 and Galicia corner building located at soft soils of Niños Héroes District

The efforts done in the medical sector have been even less transparent, particularly in the money used to recover these facilities. Public funds from the city have not been used for hospitals, as they should be provided directly by Mexican National Health Institutions (IMSS, ISSSTE and SSA, official acronyms in Spanish). No official financial and technical reports have been provided so far from these institutions. However, actions on the reinforcement and rehabilitation of several of these facilities have been documented by the press; fortunately, many of them just on time to attend the COVID-19 pandemic. The only information available on the money spent in restoring medical facilities in Mexico City is from the private fund [11]. So far, with the private fund, in Mexico City 3 new replacing 


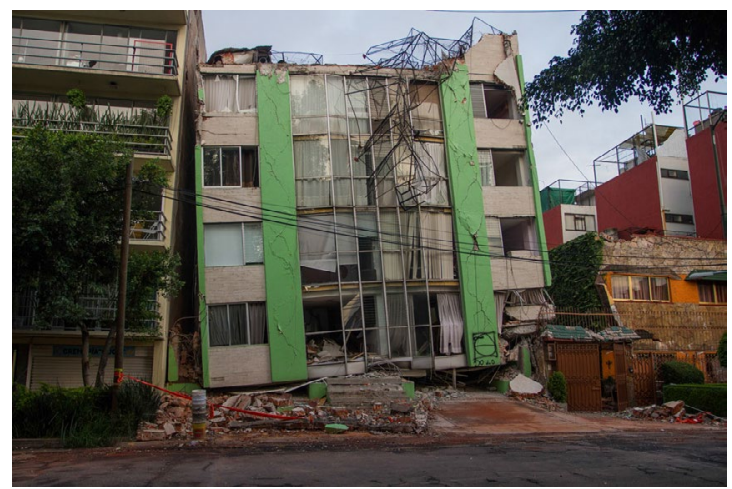

(a) Rebsamen 241 (center) and Rebsamen 245 (left) buildings

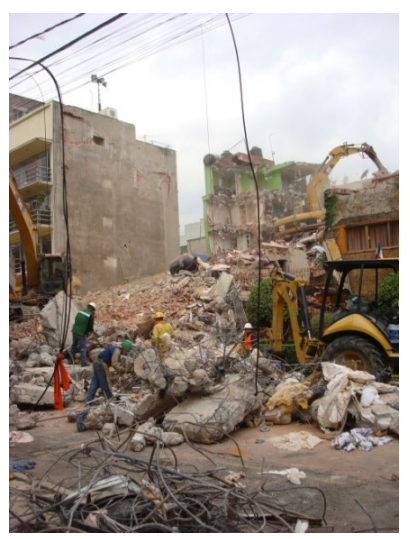

(c) September 28, 2017

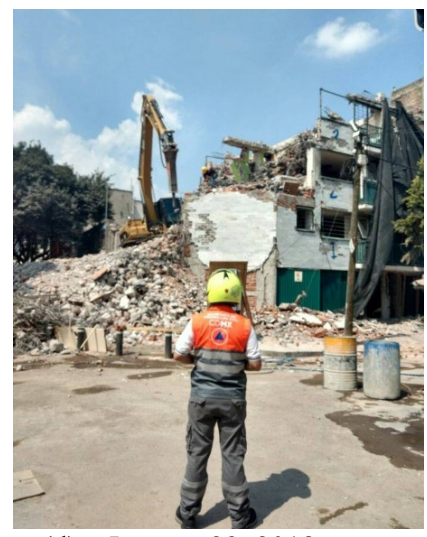

(d) January 23, 2018

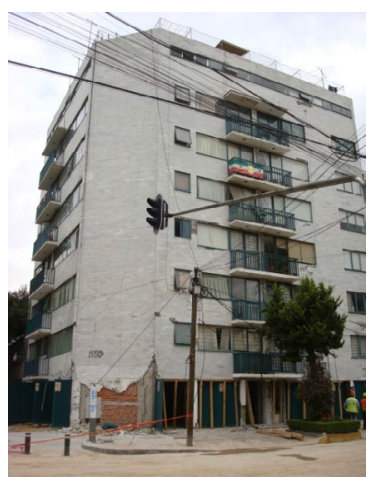

(b) Rebsamen 249 building

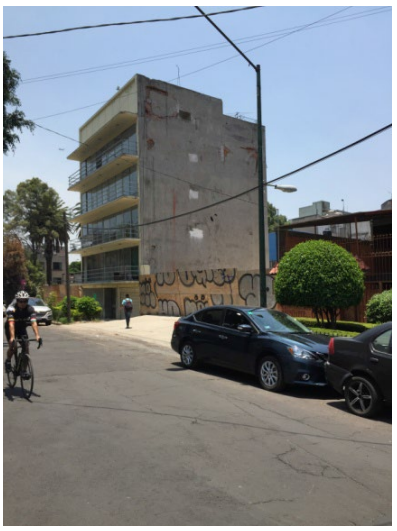

(e) August 9, 2020

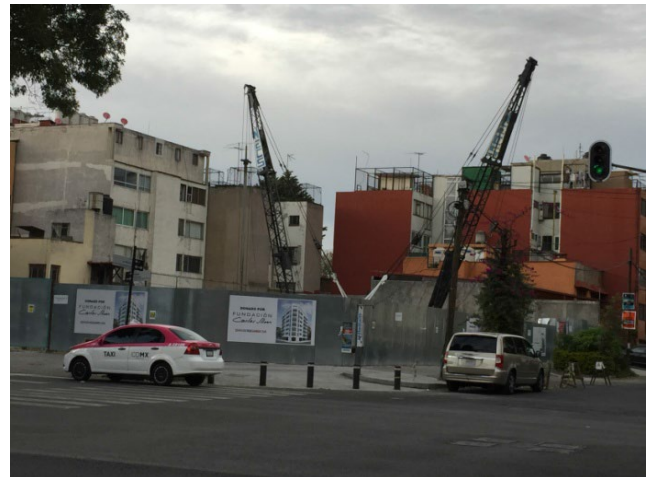

(f) February 6, 2020

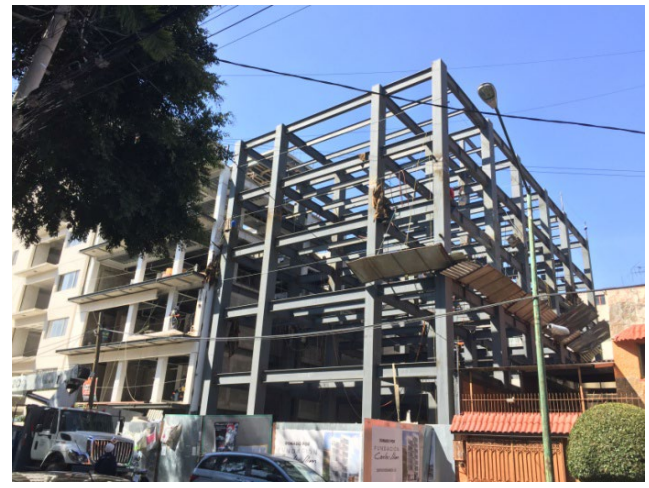

(h) October 25,2020

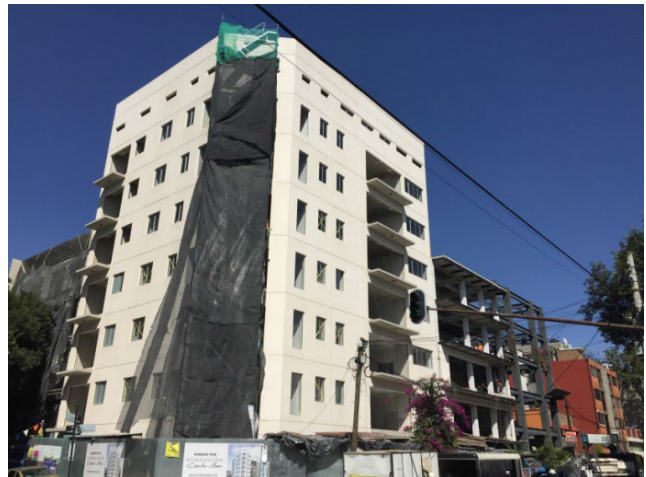

(g) October 25, 2020

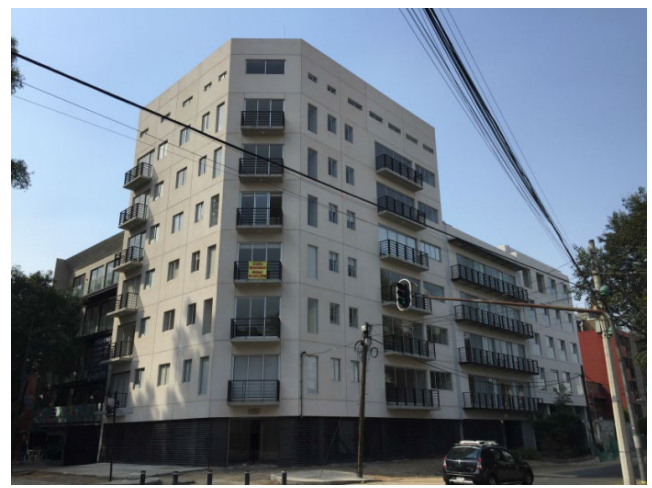

(i) February 28, 2021

Fig. 13 Recovery process of Rebsamen 241, 245 and 249 buildings located at soft soils of Narvarte Poniente District 


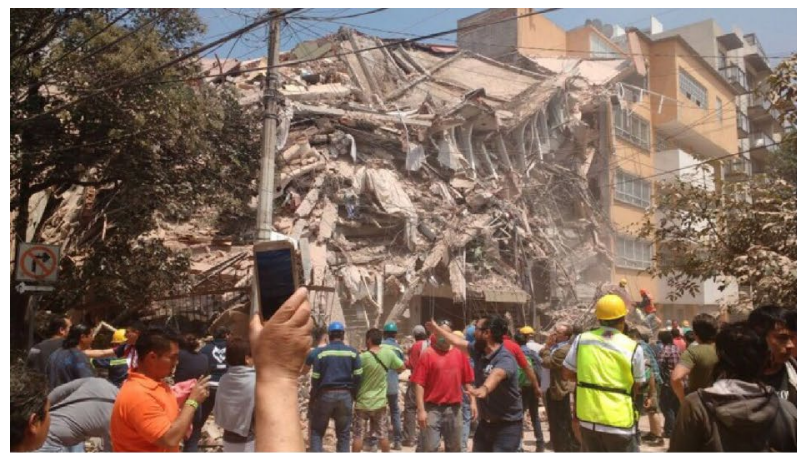

(a) September 19, 2017

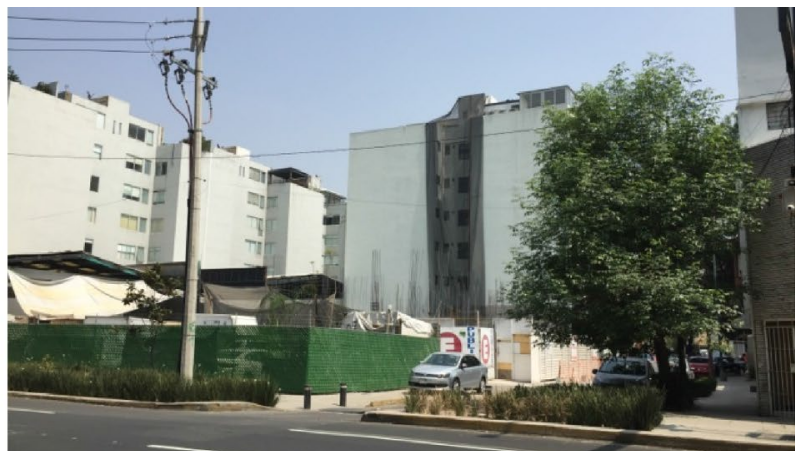

(b) March 6, 2021

Fig. 14 Status of the collapsed Escocia 4 and Gabriel Mancera corner building and Escocia 10 demolished building located at transition soils of Del Valle District

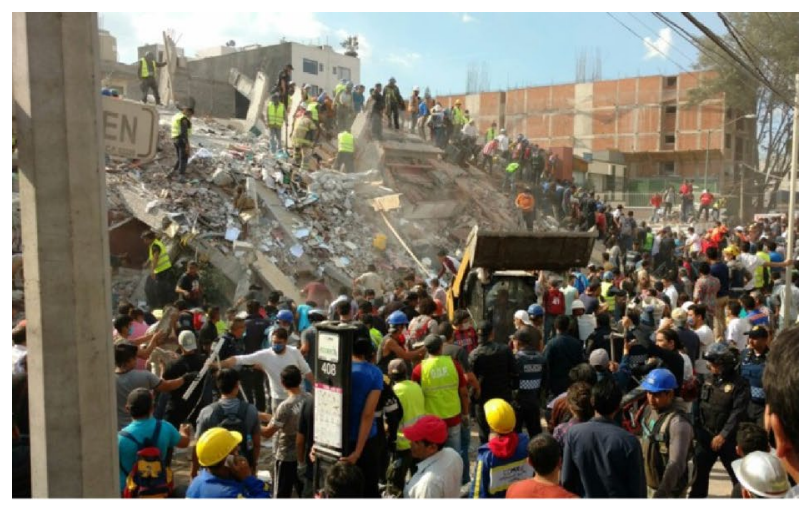

(a) September 19, 2017

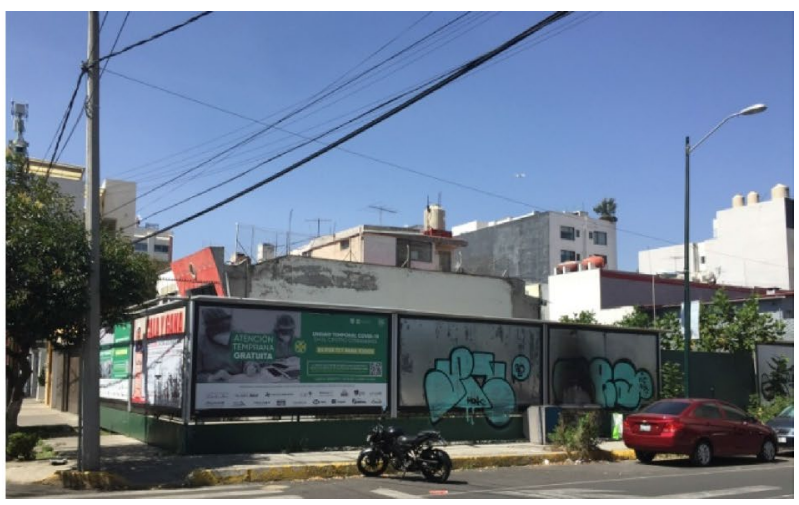

(b) October 25, 2020

Fig. 15 Status of the collapsed Prol. Petén 915 and Zapata corner building located at transition soils of Santa Cruz Atoyac District

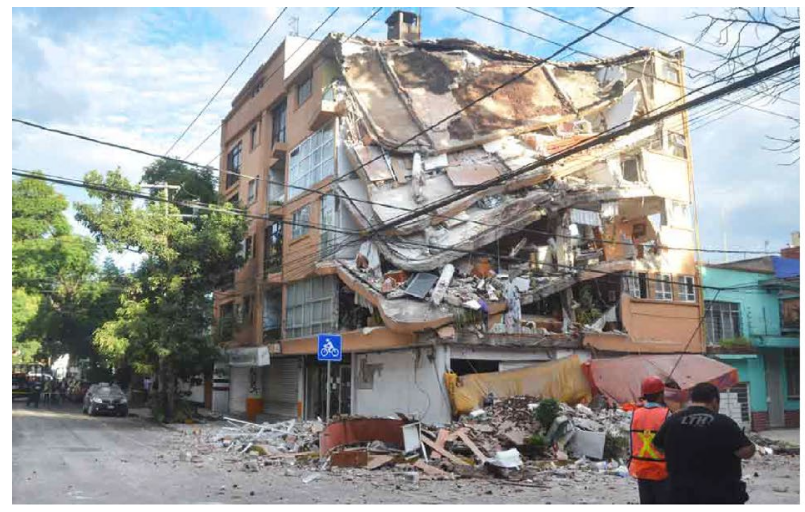

(a) September 19, 2017

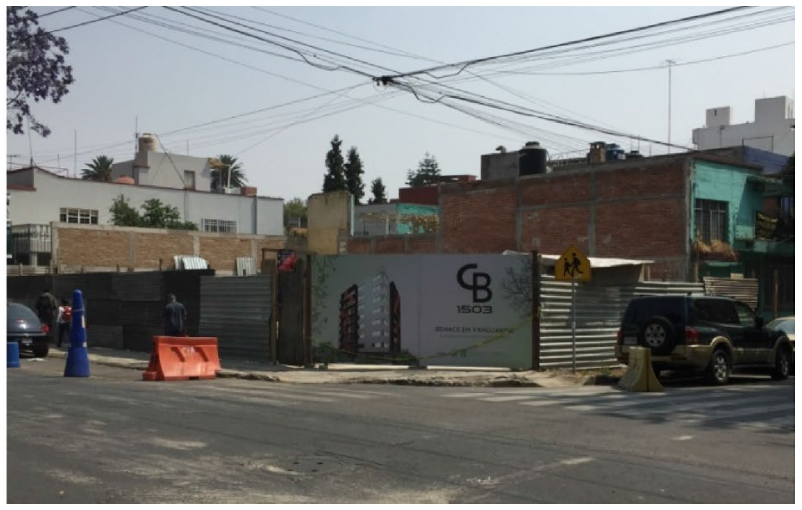

(b) March 6, 2021

Fig. 16 Status of the partially collapsed Concepción Beístegui 1503 and Yacatas corner building located at soft soils of Narvarte Poniente District

facilities (from the demolished ones, Table 1) have been built and 9 were completely rehabilitated, so these 12 facilities are under operation. One of the main public hospital buildings (medium damage) is currently under a retrofit process with this private fund. So far, the amount of money spent on these actions for these 12 facilities is 


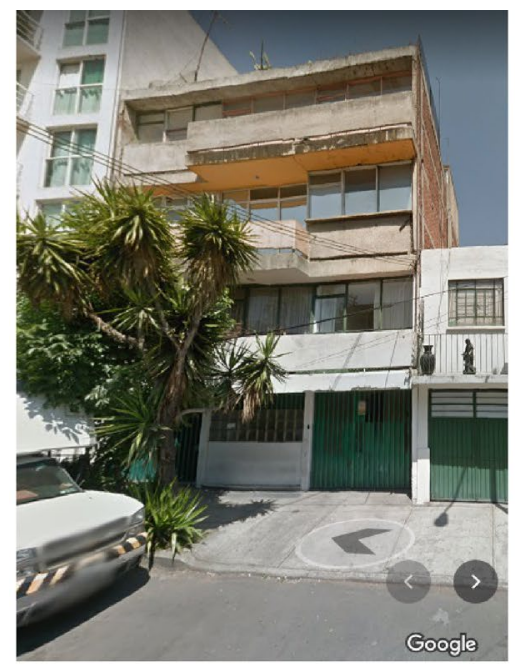

(a) Dec. 2013 (Google Maps)

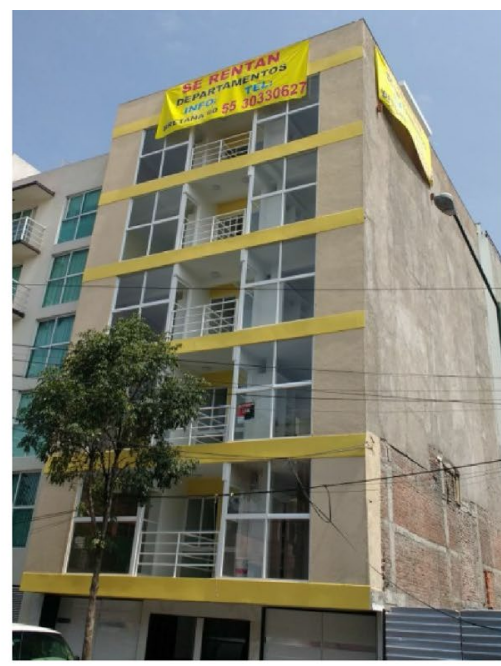

(b) January 2016 (Twitter)

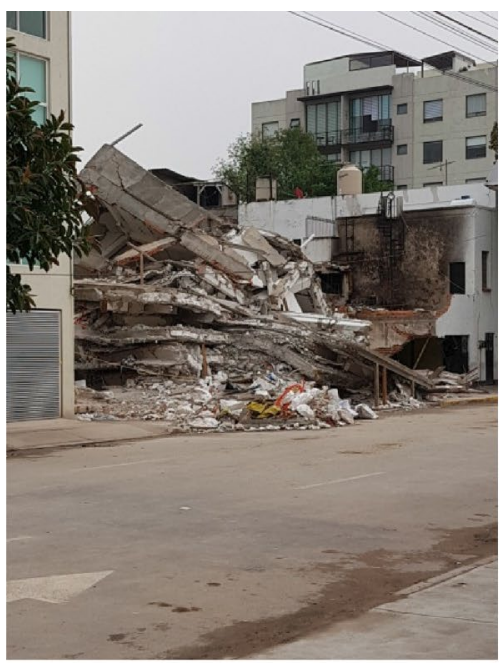

(c) September 19, 2017

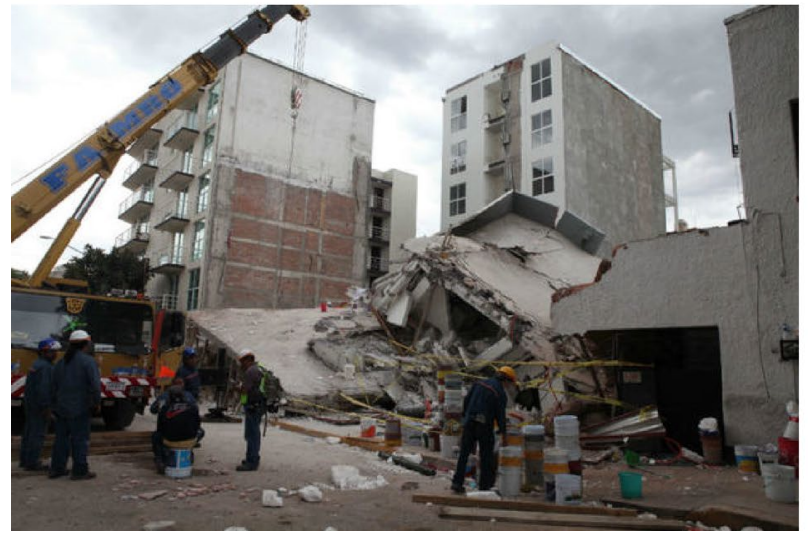

(d) September 20, 2017

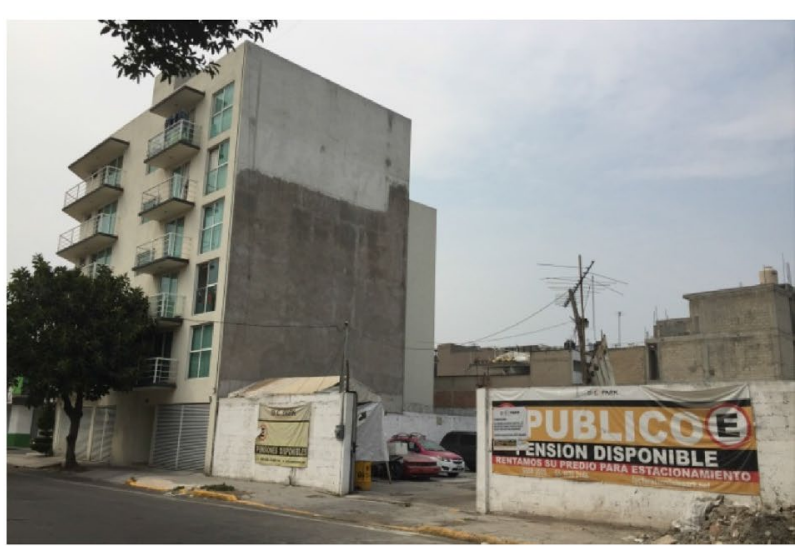

(e) March 6, 2021

Fig. 17 Status of the collapsed Bretaña 90 building located at soft soils of Zacahuitzco District

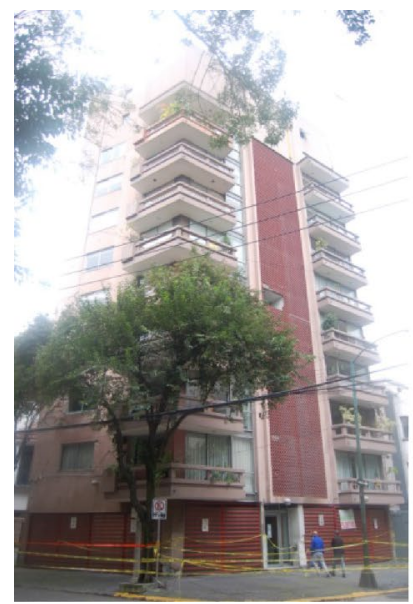

(a) September 2017

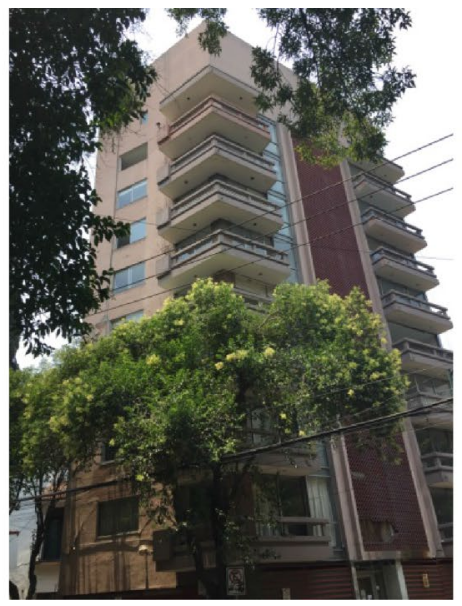

(b) May 12, 2019

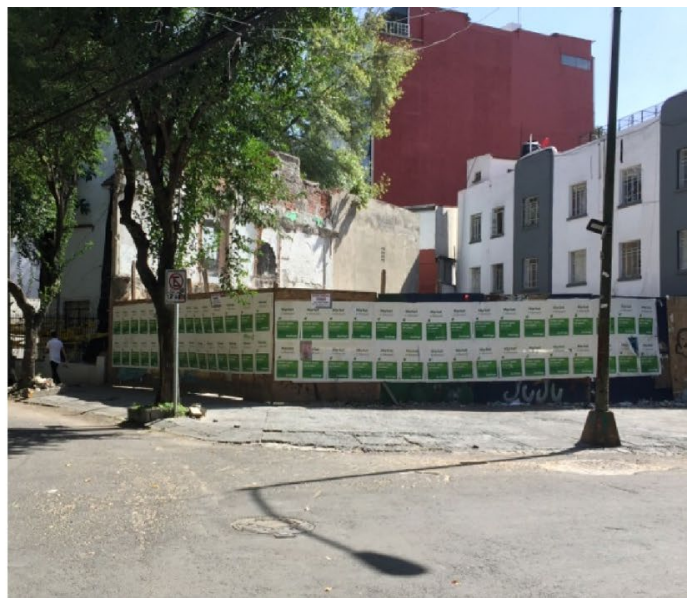

(c) October 25, 2020

Fig. 18 Status of the heavily damaged and demolished Av. México 4 and Plaza Popocatépetl building located at soft soils of Hipódromo Condesa District 


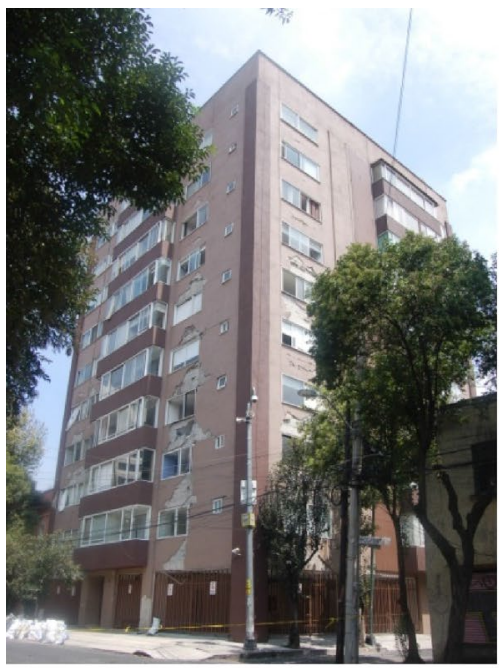

(a) September 25,2017

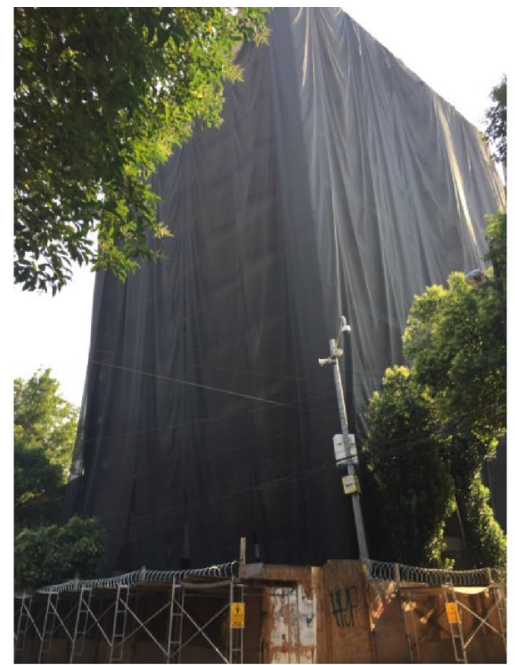

(b) May 12, 2019

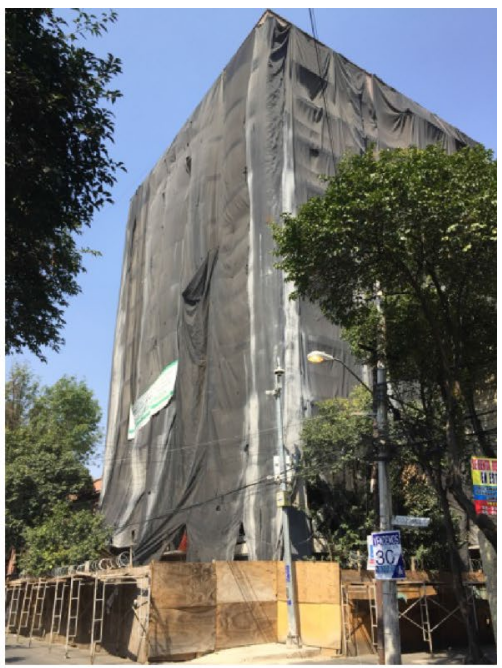

(c) February 28, 2021

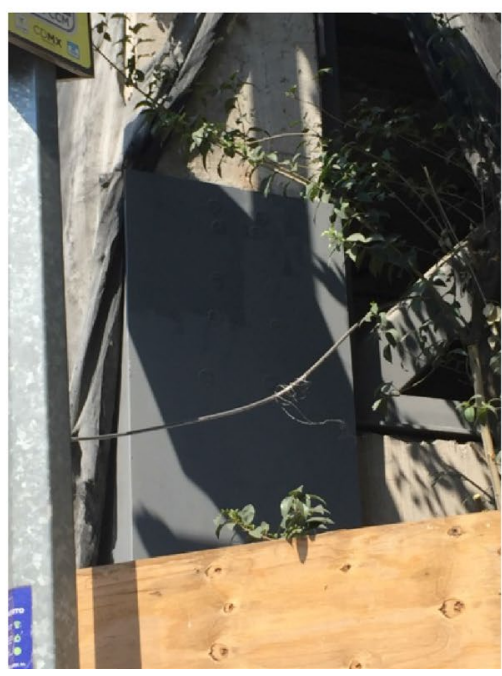

(d) February 28, 2021

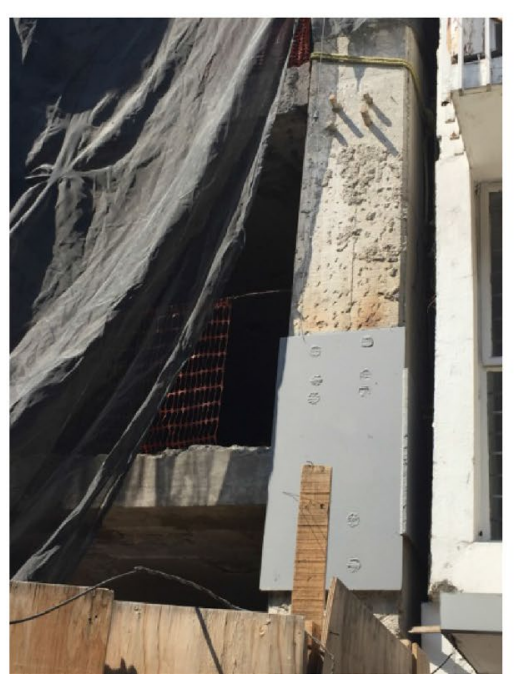

(e) February 28, 2021

Fig. 19 Status of the highly damaged Cozumel 52 and Cda. Salamanca building located at soft soils of Roma Norte District, currently under construction of a retrofit project

close to 76 million pesos (3.7 million dollars) from the private sector. Unfortunately, there is one important public hospital building from the demolition list that it is not recovered yet, and another private building used for medical facilities which was demolished and it has not been replaced yet.

The slowest and least transparent sector on recovery is the office building sector, as many of the severely affected buildings were privately owned buildings rented to both private and public offices and then, public funds are not available to rehabilitate them. So far, most of the recovered office buildings correspond to government-owned buildings (federal and local governments), but not all of them. In particular, heavily damaged buildings and collapsed office buildings are not yet recovered or even under planned retrofit-strengthening projects. A similar story happened with heavily damaged privately-owned office and commercial buildings after the September 19, 1985 earthquake, as a large inventory of close to 200 buildings of these characteristics were not recovered and remained in their damaged status for decades.

For the "other" sector category, most of the recovery has been done in public facilities (airport buildings and jails), religious buildings and hotels, and in much lesser extent in privately owned commercial buildings. There is no public data available on the amount of money spent on recovering such facilities.

It is interesting to try to measure how much these reconstruction efforts done up to March 2021 (42 months after the earthquake) is helping to improve the seismic resilience of Mexico City if an earthquake scenario similar to the one 
Table 2 Recovered structures in Mexico City up to March 2021 from the considered inventory (Table 1)

\begin{tabular}{|c|c|c|c|c|c|c|c|c|c|c|c|c|}
\hline \multirow[t]{2}{*}{ Damage Tag } & \multirow{2}{*}{$\begin{array}{l}\text { House } \\
N_{H}\end{array}$} & \multirow{2}{*}{$\begin{array}{l}\text { "Vecindad" } \\
N_{V}\end{array}$} & \multicolumn{2}{|c|}{ Apartment } & \multicolumn{2}{|c|}{ Office } & \multicolumn{2}{|c|}{ School } & \multicolumn{2}{|c|}{ Medical } & \multirow{2}{*}{$\begin{array}{l}\text { Other } \\
N_{O U}\end{array}$} & \multirow[t]{2}{*}{ Total } \\
\hline & & & $N_{A B}$ & $N_{s a}$ & $N_{O F}$ & $N_{s a}$ & $N_{S C H}$ & $N_{s a}$ & $N_{M B}$ & $N_{s a}$ & & \\
\hline$c d$ & 170 & 27 & 21 & 6.26 & 1 & 6.55 & 15 & 3.50 & 3 & 5.20 & 4 & 241 \\
\hline$h d$ & 298 & 55 & 100 & 6.07 & 7 & 7.61 & 52 & 2.54 & 6 & 6.29 & 21 & 539 \\
\hline$m d$ & 212 & 27 & 14 & 6.38 & 25 & 8.57 & 56 & 2.54 & 30 & 4.36 & 40 & 404 \\
\hline Sum & 680 & 109 & 135 & & 33 & & 123 & & 39 & & 65 & 1184 \\
\hline
\end{tabular}

experienced during the September 19, 2017 earthquake strikes soon again. For this purpose, the inventory of 2458 structures (Table 1) was considered. Crossing the public information on rehabilitated houses, vicinities, apartment buildings, schools and hospitals described above with those considered in this inventory, plus information obtained by the authors from programmed fields surveys during these following 42 months (described in the next section) and news media on other buildings, the number of fully recovered structures belonging to the considered 2458 structures is reported in Table 2. It can be observed in Table 2 that 1184 structures $(48.2 \%)$ have been fully recovered 42 months after the earthquake, considering all houses and "vecindades" recovered with public and private funds, and most school (96.0\%) and medical (86.7\%) buildings. Despite the great effort that it has been done in apartment buildings, the fully recovered facilities up to date represent only the $11.7 \%$ of the severely affected ones, although works are in progress to move to $41.1 \%$ in the following 24 months (Fig. 10a). Given the previous recovering experience after the 1985 earthquake, it is expected that the last sector to be recovered (and perhaps not to 100\%) is the office and commercial building sector, as it depends on different economic/investment variables hard to consider and quantify. For example, sometimes the owner of a private building decides either to sell the land or have a much different use, or simply leaves the seriously damaged building in that status for years (as commented earlier).

To try measure the recovery and adaptive resilience up to time $t_{j}$ (Fig. 9), where $t_{j}=42$ months, to keep it simple, Eqs. 1-12 were again used together with the data gathered from the recovery effort and summarized in Table 2. Using the same procedure described earlier, $N_{e q}=125,568$ was roughly assessed, which in relative terms of the existing cadastre of structures for Mexico City, represents a 8.36\% recovery of the seismic resilience in the built environment after the September 19, 2017 earthquake. However, it is worth noting that most new and rehabilitated structures are designed to satisfy the current 2017 building code which fully covers the September 192017 earthquake scenario, this is, a $100 \%$ resilience is expected. Then, it should be fair enough to consider that the adaptive resilience of these recovered structures is higher, and then, it should be multiplied by the inverse of the considered $\alpha$ factor, this is, by
$1 / 0.85=1.176$, so the estimated "effective" recovery in seismic resilience is then $\delta=9.84 \%$. Therefore, it can be said that after 42 months from the September 19, 2017 earthquake, the seismic resilience of Mexico City if a similar earthquake scenario strikes soon again is $\beta+\delta \approx 79.39 \%$ (Fig. 9).

It can be concluded that it will take a much longer time to fully recover the entire affected built environment importantly damaged during the September 19, 2017 earthquake to be resilient again to a future strong earthquake event. The previous experience after the September 19, 1985 earthquake is that about $80 \%$ of the importantly damaged inventory was recovered within 7 years, and about $20 \%$ of them were finally lost by many circumstances (legal problems, lack of investment of affected private owners, abandoned damaged buildings, land used as public parks or parking lots, etc.). For example, for the 1985 earthquake, Path C (Fig. 9) was achieved after 7 years. How long it will take this time to recover even better (Paths A and B, Fig. 9)? Perhaps a similar time frame. However, the final goal should not be just to recover to the previous status before the earthquake struck (Path B, Fig. 9), but to improve the seismic resilience of the inventory of structures to make Mexico City a much more resilient city for future strong earthquakes (optimistically, Path A, Fig. 9). Then, several strategies are needed to achieve this ambitious goal, which include not only to recover all the damaged structures. Preventing measures should be taken, such as strengthening/retrofitting a larger inventory of old structures closer to current standards, as well as replacing some of the old structural inventory with newer facilities designed according to modern building codes, among other pertinent actions.

\section{Examples of the recovery process in apartment buildings in Mexico City}

To illustrate and document the recovery process with subject buildings instead of just reporting and processing global numbers, the authors selected some iconic collapses of apartments buildings which appeared in all Mexican news media (formal press, television, internet, etc.) the same day the earthquake struck, as well as iconic buildings which 
grabbed the attention of the news media later also and were demolished or are being retrofit.

\subsection{Multifamiliares Conjunto Urbano Tlalpan housing complex}

One of the collapses which immediately caught the news media attention was the one of 1-C building of Multifamiliares Conjunto Urbano Tlalpan housing complex (Fig. 11a), where unfortunately nine people died. This ten-building housing complex was inaugurated in 1957 and buildings were designed according to the 1942 code. These buildings had five stories used mostly for housing, but in some buildings, there were additional "service rooms" at the roof level which occupied more than 50\% the available area at the time of the earthquake, so for structural dynamics purposes, they were closer to six-story buildings. The structural system used was composed at the first story of traditional reinforced concrete moment frames (columns and beams) with strong reinforced concrete ribbed slabs, but the following upper stories were structured by internally confined masonry walls (hollow clay units where tie-columns are casted inside at the wall ends and wall intersections) with reinforced concrete slabs. It is worth noting that masonry walls were deficiently confined in doors and window openings according to modern standards [14]. The foundation system was a reinforced concrete mat foundation $2 \mathrm{~m}$ in depth composed of deep ribbed foundation beams and bottom inverted shells. This housing complex is located in the south of Mexico City in transition soils, in fact, very close to DX37 station (about $300 \mathrm{~m}$ in straight line towards the east, Fig. 3), where very strong ground motions were recorded and very high spectral accelerations were obtained (Fig. 7).

During the September 19, 2017 earthquake, 1-C building completely collapsed but the first story (Fig. 11a), which was used for public offices. One of the particularities of these buildings, including 1-C building, is that they have very long rectangular plans ( $56.4 \mathrm{~m}$ by $7.75 \mathrm{~m}$ approximately), with an aspect ratio close to 7, which favors uneven responses of interior and exterior resisting confined masonry wall elements due to diaphragm flexibility, despite the fact of having a 11-cm-thick reinforced concrete slab. The collapse of the building was primarily because the wall density in the short direction was not enough to resist the subjected seismic forces, as shown in detailed 3D analyses of buildings similar to 1-C building [18]. No significant soil settlements were observed and measured [18]. The remaining of 1-C building was completely demolished by the end of January 2018 (Fig. 11b).

Few post-earthquake material testing was conducted for the remaining buildings, where it was found that the concrete of the existing slabs was of excellent quality, having $f^{\prime}{ }_{c}=433 \mathrm{~kg} / \mathrm{cm}^{2}(42.5 \mathrm{MPa})$ in the average. After detailed post-earthquake evaluations done by this specialized structural engineering design firm, it was found that from the remaining nine apartment buildings, six of them experienced medium damage (yellow category) and three of them experience low damage (green category). After detailed structural evaluations of all subject buildings using 3D mathematical models [18] to evaluate their future structural safety condition according to the new building code for the city [17], the decisions taken were the following: (a) design a strengthening scheme for the remaining nine apartments buildings to satisfy current building standards in Mexico City, and (b) do a formal new design according to NTCS-2017 [17] for the collapsed 1-C building.

The strengthening scheme designed for the remaining nine buildings consisted of constructing new reinforced concrete wall L segments (flanges $1 \mathrm{~m}$ long) $15 \mathrm{~cm}$ in thickness at the corners of the building (Fig. 11c, d) and of $\mathrm{T}$ cross section (flange and web $1 \mathrm{~m}$ long each) along the perimeter of the plan spaced around every $8 \mathrm{~m}$, tied with new reinforced concrete beams $20 \times 50 \mathrm{~cm}$ (Fig. 11d) and received by new reinforced concrete footings linked at the bottom to the existing shell foundation slab. To insure continuity, existing story slabs were locally demolished at those zones and new slab segments with more steel reinforcement were armed and casted, taking care of preparing surfaces for good bonding between old and new concrete. The specified compressive strength for the new reinforced concrete elements was $f^{\prime}{ }_{c}=250 \mathrm{~kg} / \mathrm{cm}^{2}(24.5 \mathrm{MPa})$. Existing old hollow masonry bricks within the perimeter were replaced with newer ones of similar characteristics. Retrofit works started on July 2018 by demolishing locally the corner and perimeter areas (e.g. Figure 11c) and it took 20 months to finish the retrofit project. On February 8, 2020, these buildings were formally given back to their owners (Fig. 13d-f), being the first building complex to be fully recovered 28 months after the earthquake struck.

The structural project for the new 1-C building (Fig. 11e) basically respected as much as possible the architectural style of the remaining buildings, but reinforced concrete flanged walls ( $\mathrm{L}$ and $\mathrm{T}$ ) and beams were used in the perimeter and in the interior hollow clay bricks were used for partition walls. Unfortunately, city authorities have been hermetic about further details for the structural projects of this new building. Eco-friendly technologies such as solar water heaters and pluvial water collectors were incorporated to this new building only (Fig. 11f).

\subsection{Niños Héroes 173 and Galicia corner building}

Unfortunately, the collapse of this first soft story, corner apartment building, which history the first author knows very well as he has lived a block and a half from this building for most of his entire life, it was expected (the chronicle 
of a foretold collapse). The building (Fig. 12) was originally a four-story apartment building (for rent) built in 1951 according to the 1942 code. It was composed of a non-ductile reinforced concrete moment frame with ribbed reinforced concrete slabs and masonry brick infills at the boundary frames, so it was the typical corner building which has two flexible open façades (frames and large windows) forming and $\mathrm{L}$ and two stiff boundary frames composed of frames with brick infills (forming the other closing L). Originally, the first floor was much more open, as it used to have a pharmacy occupying all the floor area, so the first soft and weak story potential was high. In addition, the building originally had other two irregularities, it had a C-plan because of ventilation-illumination purposes and it was slender in one direction $(H / L>3)$, where it was also weakly redundant (1-bay frames only). The building is located in soft soils; about $500 \mathrm{~m}$ in straight line towards the south and east from the well-known SCT2 station (Fig. 3).

This building was seriously damaged after the September 19, 1985 earthquake, where cracks due to torsional response were evident in frames and brick infills, and an important tilting towards the west and south was evident. The building was closed for about 15 years. However, surprising as it may seem, the buildings was not demolished or being part of a serious retrofit project. Instead, in 2001, it was the subject of minor local reparations on the frames and replacing of some masonry walls, and adding a "light" additional fifth floor. The original owners then rented this building to a private computer school (despite of formal legal complains from their neighbors). The school did not last long, as after a small earthquake, they decided to move away from this building. Then, the building was only remodeled to have six apartments and "a penthouse", which were sold to interested families. These modifications increased the global slenderness, tilting and introduced a setback irregularity.

The subject building looked as shown in Fig. 12a before the September 19, 2017 earthquake struck, where irremediably collapsed (Fig. 12b) and one person died, unfortunately for the described professional negligence. This negligence could have been avoided if a robust monitoring process enforced by the local authorities of Benito Juárez District had taken place. This was one of the buildings which were completely demolished quickly, as 5 days after the earthquake the land property was already cleaned (Fig. 12c) and it took 2 years before the construction works for the new building started (Fig. 12d).

The new five-story building is composed of ductile moment-resisting steel frames (Fig. 12e, f) which it was designed and built according to NTCS-2017 with the trust fund coordinated by the private sector [11]. It can be observed that an effort was done to improve the redundancy in the short direction (Fig. 12e, f) with respect to the collapsed building (Fig. 12a). Exterior cladding (Fig. 12g) and partition walls were made of light cardboard-like construction materials and, after 14 months of construction, the building was finished in November 2020 [11] and given back to their owners in December 2020.

\subsection{Rebsamen 241, 245 and 249 buildings}

A very interesting recovering process is the one that it has been conducted for three neighboring apartment buildings which experienced different extent of damage during the September 19, 2017 earthquake. These buildings were located within the soft soils of Narvarte Poniente District, approximately $1 \mathrm{~km}$ in straight line to the south of station CJ03 (Figs. 3, 8). The Rebsamen 241 building was a 5 -story RC building composed of columns and flatslabs and an important density of clay masonry partition walls and it was built in 1980 according to the 1976 code. This building had and I-shaped plan and experienced a clear soft first story collapse (Fig. 13a); unfortunately, one person died. Its neighboring building towards its south or left (Fig. 13a) was Rebsamen 245 building, a 5-story RC flatslabs and columns structural system which had additional masonry laundry rooms that worked as a six-story setback (Fig. 13e) from the structural dynamics viewpoint. This building was constructed in 1965 according to the 1957 code and experienced medium damage in its interior (yellow code), primarily because of structural pounding with Rebsamen 241. Besides, the building exhibited some tilting after the earthquake. Next to the left (south) of Rebsamen 245, it was the 8-story Rebsamen 249 and La Morena soft story and corner building (Fig. 13b), with a structural system composed of RC flatslabs supported by columns. It was built in 1960 according to the 1957 code and during the earthquake experienced high structural damage in the columns of the first story (concrete crushing and spalling, bucking of longitudinal steel bars, opening of stirrups, etc.), besides massive damage in the masonry walls inside at all stories. In addition to the corner configuration and the soft story, the building had two reentrant corners for illumination and ventilation purposes, so the plan looked like an F plan with thick web and flanges, besides of having eccentric stairs and elevator shafts. The building exhibited an important tilting towards the south after the earthquake. Before the earthquake, a foundation emersion around $30 \mathrm{~cm}$ was evident.

The first building to be completely demolished was Rebsamen 241, as demolition works started within the end of September 2017 (Fig. 13c) and finished in the first week of October 2017. After a reviewing process where it was decided that the building should not be retrofitted, the second building that was demolished was corner building Rebsamen 249 starting in January 2018 (Fig. 13d) and ending in February 2018. Interesting enough, Rebsamen 245 was supposed 
to be retrofitted, and therefore, it was waiting for its retrofit project up to August 2019 (Fig. 13e). However, in a very wise decision taken in September 2019, the private foundation took care of the reconstruction of these three buildings [11] and then, Rebsamen 245 was demolished before the end of 2019 , so the reconstruction works of these three buildings could be simultaneously and efficiently started in January 2020 by building their new foundations (Fig. 13f) and then erecting corner building Rebsamen 249 first (Fig. 13g), Rebsamen 245 building second (Fig. 13g, h) and Rebsamen 241 last (Fig. 13g, h). The structural system for all these new buildings is composed of ductile moment-resisting steel frames (Fig. 13g, h) which were designed and built according to NTCS-2017, as all new buildings recovered with the trust fund coordinated by the private sector [11]. Precast exterior claddings (Fig. 13g, i) and light partition walls were included. Rebsamen 249 building was finished in December 2020, then Rebsamen 245 was finished in January 2021 and finally Rebsamen 241 was finished in March 2021 [11]. The three finished new buildings are shown in Fig. 13i.

\subsection{Escocia 4 and Escocia 10 buildings}

The recovering process for others famous and well covered by the press and media collapsed buildings has not been yet as fortunate and successful as the ones described for Multifamiliares Tlalpan (Fig. 11) and the Niños Héroes corner building (Fig. 12).

One case is the collapsed Escocia 4 and Gabriel Mancera first soft-story, corner building (Fig. 14a), a seven-story reinforced concrete building (columns and flatslabs) with a long equivalent eight-story setback and an L plan (thick flanges), where unfortunately ten people died. It was built in 1975 according to the 1966 code located in transition soils of Del Valle District near to station AU46 (Figs. 3, 7). The neighboring five-story building at Escocia 10 (also a columnflatslab RC building) was heavily damaged, among other reasons, because of the structural pounding and the collapse progression of the corner Escocia 4 building. Then, it was also immediately demolished starting in October 2017. Up to March 2021, the space for the Escocia 4 corner building is temporarily being used as a parking facility, and the reconstruction works for Escocia 10 building with public funds has just been started, apparently a RC structural solution (Fig. 14b).

\subsection{Prol. Petén 915 and Zapata building}

A similar story to the Escocia 4 building can also be told for the collapsed Prol. Petén 915 and Zapata soft first story, corner building (Fig. 15a), an eight-story RC building (columns and flatslabs) located in transition soils of Santa Cruz Atoyac District near to station A024 (Figs. 3, 7), where unfortunately ten people died. This 1977 building was designed according to the 1976 code. The building had a C-plan layout for ventilation and illumination purposes, a last-story setback and eccentric location of stairs and elevator shaft. In its progression to collapse (due to torsion), this building pounded the neighboring house at Prolongación Petén street as well as the neighboring house along Zapata Avenue. The remaining of the building was demolished and the ground clean as early as September 282017 (not shown). Up to the last visit in October 25, 2020, no works have been started yet (Fig. 15b), but it is among the 390 apartments buildings which it is going to be reconstructed with public funds from the city.

\subsection{Concepción Beístegui 1503 and Yacatas building}

Another building which partial collapse was well covered by the new media starting September 19, 2017 was the six-story corner building located at Concepción Beístegui 1503 and Yacatas (Fig. 16a) at the soft soils of Narvarte Poniente District, around $800 \mathrm{~m}$ in straight line to the south and west of the well-known SCT2 station (Figs. 3, 8), where fortunately no one died. This building was constructed in 1947 and design according to the 1942 code, and the structural system was composed of RC columns with heavy and solid RC flatslabs and an important amount of clay masonry partition walls. Although the building had a soft first story potential, the partial collapse was primarily due to torsional effects, as besides of having a typical corner building configuration (open front facades and infill frames in the boundary frames with neighboring structures), there was an evident eccentric last-story setback (Fig. 16a). The building was completely demolished by the end of November 2017 (not shown). The land was not used for more than 3 years, and reconstruction works with funds from the city just started in March 2021 (Fig. 16b), after solving some legal issues.

\subsection{Bretaña 90 building}

One of the collapsed buildings which it is worth mentioning and also grabbed the press media is the 6-story Bretaña 90 building (Fig. 17) at the soft soils of Zacahuitzco District, about $1.5 \mathrm{~km}$ in straight line to the east and south of SCT2 station (Figs. 3, 8), where unfortunately one person died. Originally, there was and old four-story deficiently confined masonry brick building at the front of the land built in the 1980s up to 2014 (Fig. 17a). The original building was sold, and according to the neighbors, a six-story building was then renovated and advertised for rent as a "new building" in January 2016 (Fig. 17b). However, this "new building" really was erected by using a great portion of the former old structure (apparently the first two stories, according to the 
neighbors and the rubble evidence, Fig. 17c) and adding additional four completely new stories using multiperforated industrialized clay bricks (to have interiorly confined masonry walls) and renovating all the floors systems using the more modern version of a RC flatslab system: reduced size $\mathrm{RC}$ ribs with cast-in place thin RC topping and very large and wide styrofoam blocks (Fig. 17c). It is worth noting that according to the ruling seismic code of Mexico City, this cannot be done without a formal engineering design approved by the political district of the city where the building is located. According to the city official records, this was not done, so it was a clear act of corruption.

As a consequence, the Bretaña 90 building completely collapsed during the September 19, 2017 earthquake (Fig. 17c, d), as besides lacking authorized structural and geotechnical engineering projects from the city, the building has a clear weak and soft first story (Fig. 17b). In addition, it was evident from the rubble that: (a) there were weak connections between the structural walls (old and new) and the new flexible floor systems, and (b) as these new floor systems behave as flexible (and weak) diaphragms under lateral loading, the lateral flexibility for the whole structure increased, leading the structure to resonant responses when entering in the nonlinear range of response. Given the documented corruption act, city authorities are taken legal actions by prosecuting the people responsible for signing the structural project and responsible for their construction, and no public funds are going to be used for its reconstruction. As a consequence, the land is currently being used as a parking facility and it is on sale (Fig. 17e).

\subsection{Av. México 4 and Plaza Popocatépetl building}

This 11-story, soft-story corner building with pentagonal plan was built in 1975 according to the 1966 building code (Fig. 18). It was located in soft soils of Hipódromo Condesa District, about $500 \mathrm{~m}$ in straight line to the south and slightly to the west of station CI05 (Figs. 3, 8). The structural system was RC columns with waffle flatslabs with infill masonry walls at the neighboring perimeter and confined masonry wall stripes at front facades. The building was severely damaged because of torsional response and structural pounding with a neighboring three-story unreinforced masonry house to the left (Fig. 18), so in addition to the extensive shear cracking in the confined masonry walls at the front facades (Fig. 18a, b), there was local heavy pounding damage and shear cracks at most columns of the soft first story. The building exhibited tilting after the earthquake. Despite the fact of the severe structural damage just after the earthquake (Fig. 18a), the building remained evicted up to 2019 (Fig. 18b) and finally its demolition took place in 2020 (Fig. 18c). The building is awaiting its reconstruction project with public funds from the city [20].

\subsection{Cozumel 52 and Cda. Salamanca building}

This ten-story, soft story, corner building (Fig. 19) with an $\mathrm{L}$ plan of thick legs is located in the soft soils of Roma Norte District, about $300 \mathrm{~m}$ in straight line to the west of station CI05 (Figs. 3, 8). It was built in 1974 according to the 1966 code and the structural system was RC columns with flatslabs (using hollow concrete blocks as lightening material) with confined masonry wall stripes at front facades (Fig. 19a) and masonry infill walls at neighboring boundaries. The building experienced soft-story and torsional structural damage during the September 19, 1985 earthquake, where among other severe damage, the corner façade column at the first story partially collapsed. After the 1985 earthquake, the building was leveled up first and then locally reinforced at the first story, by replacing the partially collapsed column, jacketing all remaining first story columns and adding four reinforced concrete shear walls (two in each orthogonal direction) to try to reduce both the soft story potential and the first story torque.

During the September 19, 2017 earthquake, this building was importantly damaged again (high damage or red category, Fig. 2c), although in much lesser extent than in 1985, being damaged some of the boundary ribs of the flatslabs from stories 2-6 (Fig. 19a), shear cracks in boundary shear walls at the same stories and small fissures in the added RC shear walls in the first story. The building is being retrofitted using public funds from the city and the retrofit works started in 2019 (Fig. 19b). However, for some unknown reasons to the authors, the retrofit project seems to be going somewhat slow as it is still in progress (Fig. 19c-e). It seems that a more comprehensive and complete retrofit strategy is going to be implemented, by adding concentric $\mathrm{X}$ steel braces at the perimeter (Fig. 19d), locally reinforced with steel beams the slabs at these zones (Fig. 19d) and strengthen columnflatslab-bracing joints with steel jackets (Fig. 19d, e).

\section{Concluding remarks}

The focus of attention of this paper was devoted to try to quantify, in a simple manner, how resilient was the built environment in Mexico City during the September 19, 2017 earthquake and how much the resilience for a similar earthquake scenario has been recovered so far after 42 months of this earthquake event. For this purpose, global statistics of the severity of the observed damage during this seismic event gathered from well-documented and detailed damage surveys studies were used.

A starting point was to recognize that the inherent seismic resilience or quality of infrastructure of the building inventory in Mexico City before the September 19, 2017 
earthquake cannot be considered "optimal" or $100 \%$ for an earthquake of the size and magnitude of the September 19, 2017 earthquake, but a fraction of it $(\alpha)$. There are several reasons that support this argument and which are outlined within the paper. However, one outstanding by itself is to consider the large inventory of existing old structures in Mexico City (built before 1987) which design spectra were considerably surpassed all over Mexico City by the response spectra of the recorded ground motions. Although it is acknowledged that several very complex and formal vulnerability-resilient assessment analyses (with many simplification hypothesis as well) would be required for a given earthquake scenario of interest to assess a more rational value for $\alpha$, the authors optimistically considered that it might be close to $85 \%$ ( $\alpha=85 \%)$ for an earthquake of this magnitude and seismic source. This $\alpha$ factor should also depend on the magnitude and distance from the seismic source, as well as site effects, among many other relevant variables.

Then, using a detailed damage inventory of 2458 structures from medium damage to collapse compiled by the authors as input, an intuitive-yet arbitrary-measurement was proposed to estimate an equivalent number of affected structures according to their extent of damage and how their use affects or impacts the society. Using these data and the simple method explained within the paper, an equivalent number of affected structures $\left(N_{e q}\right)$ was assessed. In relative terms of the existing cadastre of structures for Mexico City at the time, a $15.45 \%$ sudden drop of the seismic resilience in the built environment in Mexico City after the September 19, 2017 earthquake was assessed. Therefore, the resilience of Mexico City for this earthquake scenario dropped to $69.55 \%$ just after the September 19, 2017 earthquake.

As also documented within the paper, 42 months after the earthquake, around 1184 structures (48.2\%) of the 2458 considered damaged structures have been recovered to full operation, all houses and "vecindades" (100\%) which were recovered using public and private funds, most school (96.0\%) and medical (86.7\%) buildings. However, despite the great effort that it has been done in apartment buildings, the fully recovered facilities represent only $11.7 \%$ of the severely affected ones, and $20 \%$ for office buildings. Using the same simplified procedure proposed to quantify the adaptive resilience on the ongoing recovery process, the recovery of these 1184 structures represents a $8.36 \%$ increase of the seismic resilience in the built environment in Mexico City after the September 19, 2017 earthquake. However, as most new and rehabilitated structures are designed to satisfy the current 2017 building code which fully covers the September 192017 earthquake scenario, a 100\% resilience is expected for these recovered facilities for a similar scenario, so their resilience is increased. Then, it was considered that the adaptive resilience of these recovered structures is higher, and it was multiplied by the inverse of the considered $\alpha$ factor, this is, by $1 / 0.85=1.176$, so the estimated "effective" recovery in seismic resilience is then $\delta=9.84 \%$. Therefore, it can be said that after 42 months of the September 19, 2017 earthquake, the seismic resilience of Mexico City for a future and similar earthquake scenario that may strike again soon raised to $79.39 \%$.

Also, the ongoing recovery process of some iconic buildings which collapses, severe damage and demolitions have been well covered by the news media have also been documented and discussed, to put into the right context the complexity of recovering this important sector to the society. As it is shown, few of these collapsed building have been recovered 42 months after the earthquake, while many others have been demolished so far and are waiting for a project and/or funds to be rebuilt and then, give them back to their owners.

It can be clearly concluded that it will take a much longer time to fully recover the entire built environment importantly affected during the September 19, 2017 earthquake to be resilient again to future strong earthquake events. For an effective earthquake resilience strategy to withstand future strong earthquakes, the final goal should not be just to recover Mexico City to its previous status before the September 19, 2017 earthquake struck. The seismic resilience of a much larger inventory of structures in Mexico City should be improved to have a much more resilient city for future strong earthquake events. Then, several strategies are needed to achieve this ambitious goal. In the particular case of Mexico City, considering also the large extent of damage observed in buildings designed with collapse-prevention codes when subjected to spectral accelerations below those assumed in their design (1987-2004 codes, e.g. [28], it is clear to the authors that to improve seismic resilience in the future: (a) it should be mandatory to use resilient-based concepts for the seismic retrofit and upgrading of existing structures (damaged or apparently undamaged), (b) new buildings should be designed using resilient-based design procedures (e.g., [26] and performance-based procedures directed to achieve operational performance objectives, (c) city authorities should start working in developing, publishing and promoting the use of a new resilient-based seismic design code in the near future, (d) the role of local city authorities (each one of Mexico City's political and administrative Districts) would be crucial in enforcing and assuring an acceptable minimum of resilience in the construction of new structures and the retrofitting of new ones, and e) coordinated programs for the structural health monitoring of typical representative buildings for the city (including old, retrofit and new buildings) should be implemented and the gathered information used to detect and correct potential structural deficiencies on time before the next strong earthquake may strike. In addition, complementary detailed vulnerability studies should be done 
to screen and prioritize the types of building construction and sectors of the city which should be attended first to improve their seismic resilience with well-planned, programmed retrofit, strengthen or replacement projects (midterm and long-term coordinated projects), where information gathered in structural health monitoring of buildings is of paramount importance. Finally, public policies on the use of the land in very poor, non-consolidated soft soils gained to the former lakes have to be more strictly regulated by city authorities, to avoid in future seismic events the enormous extent of damage observed in these regions of Mexico City.

Acknowledgements The authors want to express again their gratitude to all professionals involved in providing trustful information for the city authorities' platforms Plataforma CDMX and Reconstrucción CDMX, as well as relatives who shared important information of some damaged buildings in our developed database. Alejandro Grande Vega, Luis Angel Urbina Californias and Omar Villegas Jiménez are thanked for their previous collaboration on this research effort. The suggestions of one anonymous reviewer were germane to improve some sections of the original manuscript and are gratefully acknowledged.

\section{Declarations}

Conflict of interest On behalf of all authors, the corresponding author states that there is no conflict of interest.

\section{References}

1. Avilés J, Pérez-Rocha LE (2010) Regional subsidence of Mexico City and its effects on seismic response. Soil Dyn Earthq Eng 30:981-989. https://doi.org/10.1016/j.soildyn.2010.04.009

2. Berrón R, Pacheco MA, Valencia N, Aguilar P (2018) Análisis de las edificaciones afectadas en la Ciudad de México por el sismo del 19 de septiembre de 2017 dictaminadas por el Instituto para la Seguridad de las Construcciones. Proceedings, XXI Congreso Nacional de Ingeniería Estructural, Campeche, México, Paper No. 12-55 (in Spanish)

3. Borja-Navarrete G, M Díaz-Canales, A Vázquez-Vera, E Del Valle-Calderón (1987) Damage statistics of the September 19, 1985 Earthquake in Mexico City. In: Cassaro MA, MartínezRomero E (eds) The Mexico Earthquakes-1985 Factors Involved and Lessons Learned. ASCE Special Publication, New York, $p$ 70-77

4. Bruneau M, Chang SE, Eguchi RT, Lee GC, O'Rourke TD, Reinhorn AM, Shinozuka M, Tierney K, Wallace WA, Von Winterfeldt D (2003) A framework to quantitatively assess and enhance the seismic resilience of communities. Earthq Spectra 19(4):733-752. https://doi.org/10.1193/2F1.1623497

5. Cariolet J-M, Vuillet M, Diab Y (2019) Mapping urban resilience to disasters - a review. Sustain Cities Soc 51:101746. https://doi. org/10.1016/j.scs.2019.101746

6. Cigna F, Tapete D (2020) Present-day land subsidence rates, surface faulting hazard and risk in Mexico City with 2014-2020 Sentinel-1 IW InSAR. Remote Sens Environ. https://doi.org/10. 1016/j.rse.2020.112161

7. Cimellaro GP, Reinhorn AM, Bruneau M (2010) Framework for analytical quantification of disaster resilience. Eng Struct 32:3639-3649. https://doi.org/10.1016/j.engstruct.2010.08.008
8. DACDMX (2019) Datos abiertos Ciudad de México. Uso de suelo, https://datos.cdmx.gob.mx/explore/dataset/uo-de-suelo/ table/. Accessed 11 Dec 2019

9. Fuerza México (2020) Public information uploaded by this nongovernmental organization at the URL site https://www.transparen ciapresupuestaria.gob.mx/es/PTP/fuerzamexico_datosabiertos. Accessed 25 Mar 2020

10 Fundación ICA (1988) Experiencias derivadas de los sismos de septiembre de 1985, 1st edn. Limusa, Mexico City (ISBN 968-18 2939-5. In Spanish)

11. Fundación Slim (2020) Fundación Carlos Slim. México Unido Sismos 2017. Informe 31 de diciembre de 2020. https://funda cioncarlosslim.org/informe-de-sismos-diciembre-de-2020/. Accessed 17 Mar 2021

12. Gutierre T (1975) Historia del Nombre y de la Fundación de México, 1st edn. Fondo de Cultura Económica, Mexico City, pp 97-141 (in Spanish)

13. Macazaga C (1979) Nombres Geográficos de México, 1st edn. Editorial Innovación, México City, pp 98-101 (in Spanish)

14. NTCM-2004 (2004) Normas Técnicas Complementarias para Diseño y Construcción de Estructuras de Mampostería. Gaceta Oficial del Distrito Federal (in Spanish)

15. NTCS-87 (1987) Normas Técnicas Complementarias para Diseño por Sismo. Gaceta Oficial del Departamento del Distrito Federal (in Spanish)

16. NTCS-04 (2004) Normas Técnicas Complementarias para Diseño por Sismo. Gaceta Oficial del Distrito Federal (in Spanish)

17. NTCS-17 (2017) Normas Técnicas Complementarias para Diseño por Sismo. Gaceta Oficial de la Ciudad de México (in Spanish)

18. Olagaray C, Flores JL (2017) Estudio diagnóstico estructural correspondiente al edificio $4 \mathrm{C}$ perteneciente a la Unidad Habitacional Tlalpan. Dictamen de Seguridad Estructural, Carlos Olagaray Palacios y José Luis Flores Ruiz Ingenieros Consultores p 1-100 (in Spanish)

19. Plataforma CDMX (2018), https://plataforma.cdmx.gob.mx/. Information open up to November 2018. Currently unavailable. Accessed 30 Nov 2018

20. Reconstrucción CDMX (2021), https://reconstruccion.cdmx.gob. $\mathrm{mx} / \mathrm{censo}$. Accessed 16 Mar 2021

21. Rosenblueth E (1960) The earthquake of 28 July 1957 in Mexico City. Proceedings, 2nd World Conference on Earthquake Engineering, Tokyo, Japan, vol. 1, p 359-379

22. Rosenblueth E, Ordaz M, Sánchez-Sesma FJ, Singh SK (1989) The Mexico earthquake of september 19, 1985 - design spectra for Mexico's Federal District. Earthq Spectra 5(1):273-291. https:// doi.org/10.1193/2F1.1585523

23. SGO-DDF (1988) Sismos de 1985, Control de Edificaciones, México, DF, 1985-1988. Secretaría General de Obras del Departamento del Distrito Federal, Mexico (in Spanish)

24. Tena-Colunga A (1987) The meaning of the word México, English Research Paper, University of Illinois at Urbana-Champaign, https://www.researchgate.net/publication/265685565_The_meani ng_of_the_word_Mexico.Accessed 6 Apr 2021

25. Tena-Colunga A (2020) Moving forward from collapse-prevention seismic design towards resilient seismic design. Revista Internacional de Ingeniería de Estructuras 25(4):521-560. https://doi.org/ 10.24133/riie.v25i4.1862

26. Tena-Colunga A, Hernández-Ramírez H (2020) Resilient seismic design of steel frames with hysteretic fuses in a code-oriented format. J Build Eng 32:1-18. https://doi.org/10.1016/j.jobe.2020. 101768

27. Tena-Colunga A, Hernández-Ramírez H, Godínez-Domínguez EA, Pérez-Rocha LE, Grande-Vega A, Urbina-Californias LA (2020) Performance of the built environment in Mexico City during the september 19, 2017 earthquake. Int J Disaster Risk Reduct 51:101787. https://doi.org/10.1016/j.ijdrr.2020.101787 
28. Tena-Colunga A, Hernández-Ramírez H, Godínez-Domínguez EA, Pérez-Rocha LE, Grande-Vega A, Urbina-Californias LA (2021) Seismic behavior of buildings in Mexico City during the 2017 Puebla -Morelos earthquake. Asian J Civil Eng 22:649-675. https://doi.org/10.1007/s42107-020-00338-9
Publisher's Note Springer Nature remains neutral with regard to jurisdictional claims in published maps and institutional affiliations. 